\title{
La comunidad judía de Calatayud durante el siglo XIV. Introducción al estudio de su estructura social
}

\author{
Máximo Diago Hernando * \\ Instituto de Historia - CSIC, Madrid
}

Calatayud fue durante el período bajomedieval la segunda ciudad más poblada del reino de Aragón, después de Zaragoza ${ }^{1}$, y destacó además por ser uno de sus núcleos urbanos más dinámicos en el desempeño de funciones mercantiles y financieras ${ }^{2}$. En consonancia con ello su comunidad judía también se contó entre las más numerosas, dinámicas y prósperas del reino, según nos confirman diversos indicios. Así, por ejemplo, cuando en 1383 Pedro IV convocó a su Curia al tesorero y síndicos de las aljamas judías de sus dominios, acudieron en representación de las del reino de Aragón los nuncios de las de Zaragoza y Calatayud, Salamón Abenarrabí e Içach de Quatorze, respectivamente. Estos dos judíos permanecieron entonces con este motivo en la ciudad de Tortosa durante noventa días, e incurrieron por ello en elevados gastos, que el rey accedió a que se les compensasen mediante la entrega de 450 florines, 120 para Salamón Abenarrabí y 330 para Içach de Quatorze. Esta cantidad ordenó que se repartiese

\footnotetext{
*mdiago@ceh.csic.es

${ }^{1}$ Como consecuencia también se le reconocía por este motivo la segunda posición en rango. Así lo reconoce por ejemplo el rey Martín I en carta al justicia de Aragón, en que la califica como la más insigne del reino de Aragón después de Zaragoza. Archivo de la Corona de Aragón [= ACA], Cancillería [= C], reg. 2168 - 132v (Indicamos siempre número de registro y, seguido de guión, el del primer folio del documento), Valencia, 27-V-1402.

2 Sobre el papel de Calatayud en las rutas mercantiles del reino de Aragón, vid. mi «Desarrollo de las ciudades aragonesas fronterizas con Castilla como centros mercantiles durante el siglo XIV: Tarazona, Calatayud y Daroca», Cuadernos de Historia Jerónimo Zurita 74 (1999), 211-246. Una introducción al estudio de la estructura socioeconómica de la ciudad de Calatayud en época bajomedieval en ID., «Calatayud en la Baja Edad Media. Organización sociopolítica y actividades económicas», en Actas del VI Encuentro de Estudios Bilbilitanos (Calatayud 2005), 237-274.
} 
entre todas las aljamas judías del reino de Aragón conforme a su capacidad contributiva. Y el reparto que se efectuó nos da perfecta idea de la enorme distancia que separaba entonces a las dos grandes aljamas del reino, la de Zaragoza y la de Calatayud, de las restantes, puesto que mientras que estas dos debieron pagar 140 y 105 florines respectivamente, a las demás se les exigieron cantidades muy inferiores, que iban desde los 30 florines cargados a la de Huesca, a los 5 que se repartieron a las de Sos, Uncastillo y Tamarite ${ }^{3}$. Pero, en honor a la verdad, conviene llamar la atención sobre la ausencia, por motivos que desconocemos, de la aljama de Teruel, que también se contaba en aquellas fechas entre las principales del reino. Esto nos da idea de la elevada capacidad contributiva de la aljama judía de Calatayud, que podía ser fruto tanto de la concentración en ella de un elevado número de familias, como también de la presencia entre ellas de varias particularmente acaudaladas, y es probable que ambos factores coadyuvasen. En cualquier caso los reyes de Aragón tenían conciencia de este hecho, y así lo reconocieron expresamente en algunos documentos en que calificaron a la aljama judía bilbilitana como «uno de los principales miembros de nuestro patrimonio» ${ }^{4}$.

Por otra parte, otro significativo indicio que da idea de la magnitud que llegó a alcanzar la comunidad judía bilbilitana en el transcurso del siglo XIV nos lo proporciona la noticia que aporta Baer, según el cual a fines de este siglo las ocho sinagogas disponibles en esta ciudad ya no resultaban suficientes para atender las necesidades de la población judía y se consideró necesario edificar una novena para que los judíos que vivían en las calles más alejadas pudiesen visitarla ${ }^{5}$. Y, en otro orden de cosas, también disponemos de indicios que sugieren que desde la perspectiva del prestigio alcanzado en los planos religioso, espiritual e intelectual, la comunidad judía de Calatayud pudo rivalizar con la de Zaragoza. Es el caso, por ejemplo, de la noticia, proporcionada por Baer, de que

\footnotetext{
${ }^{3}$ Carta de Pedro IV fechada en Monzón, 31-X-1383, que se inserta en sobrecarta otorgada en Barcelona, 12-XII-1386, en ACA, C, reg. 857 - 25.

${ }^{4}$ Un ejemplo de utilización de esta expresión en ACA, C, reg. 2181 - 95v, Barcelona, 21-V1406.

${ }^{5}$ F. BAER, Studien zur Geschichte der Juden im Königreich Aragonien während des 13. und 14. Jahrhunderts (Berlin 1913), pág. 147. Por su parte A. Neuman afirma que en Calatayud llegó a haber hasta siete sinagogas, The Jews in Spain. Their Social, Political and Cultural Life during the Middle Ages (Philadelphia 1942), vol. II, pág. 150. Por fin, más recientemente, J. R. Magdalena Nom DE DÉu ha conseguido identificar diez centros de oración en la judería de Calatayud, de los cuales tres eran sinagogas, tres madrazas, y cuatro simples oratorios. Vid. su «Sinagogas, madrazas y oratorios de la aljama de Calatayud», Anuari de Filologia 14 (1991), sección E, 1, págs. 117-123, y también A. Blasco Martínez, «Las sinagogas de Aragón: Datos de los últimos diez años», en Juderías y sinagogas de la Sefarad Medieval (Cuenca 2003), págs. 210-213.
}

SeFARAD, vol. 67:2, julio-diciembre 2007, págs. 327-365. ISSN 0037-0894 
Isaac Perfet pensó en una ocasión cambiar su puesto de rabino en esta última ciudad por otro semejante en Calatayud ${ }^{6}$.

Aunque para la ciudad de Calatayud el siglo XIV fue un período cargado de turbulencias, particularmente en sus décadas centrales, cuando sufrió durante bastantes años la ocupación castellana, y se vio directamente afectada durante muchos años más por los efectos de una devastadora guerra, probablemente la más cruenta de cuantas se sucedieron en el solar hispano durante los siglos bajomedievales, la llamada «de los dos Pedros», también es cierto que a lo largo de esta centuria se reforzó su papel como centro manufacturero, mercantil y financiero, a la vez que mejoró su rango, al ser elevada de la categoría de villa a la de ciudad por merced del rey Pedro IV, en recompensa por la fidelidad demostrada durante las guerras contra Castilla.

La contribución de la comunidad judía al progreso económico de Calatayud fue en este período considerable, pues, a diferencia de lo que ocurrió en la siguiente centuria, entonces su potencial todavía no se vio apenas mermado por la sangría que más adelante representaron las conversiones de judíos al cristianismo, que experimentaron una auténtica explosión en los primeros años del siglo XV y privaron a la comunidad judía bilbilitana de muchos de sus miembros más acaudalados y emprendedores. Ciertamente, según apunta Baer, las actuaciones de la Inquisición en la década de 1320 pudieron tener efectos devastadores sobre la comunidad judía bilbilitana, obligando a muchas familias a emigrar ${ }^{7}$, pero, en caso de que así fuese, los problemas debieron quedar muy pronto superados, a juzgar por los muchos indicios sobre la prosperidad de dicha comunidad que proporciona la documentación del siglo XIV, a algunos de los cuales haremos referencia a lo largo del presente trabajo.

En función de lo dicho, entendemos que ofrece un indiscutible interés detenerse en el análisis de la trayectoria histórica de la comunidad judía de Calatayud en el siglo XIV, por tratarse del período en que culmina su fase de prosperidad, que da inmediatamente paso a una nueva fase de crecientes dificultades, que en el plazo de apenas un siglo precipitarán la definitiva desaparición de la misma, por virtud del doble proceso de la conversión al cristianismo de una parte importante de sus miembros y de la expulsión de los demás.

Con respecto a períodos anteriores, que probablemente fueron tanto o más venturosos para la comunidad judía de Calatayud como el siglo XIV, este último ofrece por otra parte al investigador la ventaja de que para su estudio dispone de

\footnotetext{
${ }^{6}$ BAER, Studien zur Geschichte der Juden, pág. 147.

${ }^{7}$ BAER, Studien zur Geschichte der Juden, pág. 159.
} 
un conjunto documental mucho más abundante y diversificado, custodiado en su mayor parte en el Archivo de la Corona de Aragón, dado que los fondos de los archivos locales, particularmente los notariales, sólo comienzan a resultar abundantes a partir del siglo $\mathrm{XV}^{8}$. De hecho los documentos que custodia este archivo que hacen referencia directa a judíos avecindados en Calatayud, o a la aljama judía de esta ciudad aragonesa en su conjunto, son extraordinariamente numerosos, pero se encuentran muy dispersos, por lo que su localización exige una importante inversión en tiempo, del que habitualmente no disponen los investigadores. Hasta que no se lleve a cabo una labor sistemática de localización y análisis de estos documentos no estaremos en condiciones de abordar la reconstrucción de la historia de la comunidad judía bilbilitana con unas mínimas garantías. Pero entre tanto no debemos renunciar a la realización de aproximaciones parciales al análisis de esta cuestión, basadas en la utilización de un corpus documental restringido, aunque susceptible de aportar informaciones de interés para el conjunto de los investigadores de la historia de los judíos hispanos. Y éste es por consiguiente el objetivo que nos hemos propuesto cumplir al redactar el presente artículo, en el que ofreceremos algunas primeras pinceladas sobre el panorama social que presentaba la comunidad judía bilbilitana en el siglo XIV, aprovechando la información reunida en las consultas realizadas hasta ahora en los registros de cancillería del Archivo de la Corona de Aragón, y en las secciones hacendísticas de este mismo archivo.

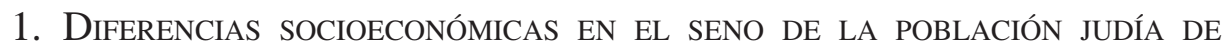 Calatayud: LaS «MANOS»}

La presencia de fuertes contrastes entre las familias judías residentes en Calatayud durante el siglo XIV desde el punto de vista de su posición económica tuvo una primera traducción entonces en la división de esta comunidad en dos

\footnotetext{
${ }^{8}$ La documentación notarial bilbilitana del siglo XV ha sido utilizada para la elaboración de varios estudios monográficos sobre familias judías de Calatayud por E. MARín PADILLA, así en su «Notas sobre la familia Lupiel de Calatayud (1482-1488)», Aragón en la Edad Media 3 (1980), 227-262; EAD., «Inventario de bienes de judíos bilbilitanos en 1492», Sef 48 (1988), 309-341; EAD., «Notas sobre la familia Constantin de Calatayud (1482-1488)», Aragón en la Edad Media 5 (1983), 219-254; EAD., «Más sobre los Constantin de Calatayud», Sef 46 (1986), 317-323; EAD., «En torno a una demanda de pago a rabí Açach Arama ante los dayyanim de Calatayud (Siglo XV)», Michael 11 (1989), 142-148; EAD., «Inventario de los bienes muebles del judío bilbilitano Salamon Ezi en 1492», Sef 48 (1988), 93-115, y en su Panorama de la relación judeoconversa aragonesa en el siglo XV: con particular examen de Zaragoza (Zaragoza 2004). También hay que hacer mención a los libros de Á. LóPez Asensio, La judería de Calatayud. Sus casas, calles y barrios (Zaragoza 2003), y Oficios de los judíos de Calatayud (Zaragoza 2007).
}

SEFARAD, vol. 67:2, julio-diciembre 2007, págs. 327-365. ISSN 0037-0894 
grandes grupos a los que la documentación cancilleresca denomina «manos». En concreto en varios documentos de la primera mitad de este siglo referidos a los judíos bilbilitanos hemos encontrados referencias explícitas a la mano «mayor», por un lado, y la mano «menor» $\mathrm{o}$ «inferior» por otro ${ }^{9}$. Y en otros documentos se constata también la utilización de la expresión «menudos» para referirse a los judíos que formaban parte de esta última ${ }^{10}$.

Las relaciones entre ambos grupos estuvieron a lo largo de esta centuria cargadas de tensión como consecuencia del hecho de que los integrantes de la mano «menor» no se resignaron a dejar totalmente en manos de los miembros de la mano «mayor» la gestión de las tareas de gobierno y administración de la aljama, como pretendían estos últimos, y por ello se movilizaron con relativa frecuencia ante el rey para que les apoyase en sus reivindicaciones, tratando de conseguir que se les tuviese más en cuenta a la hora de tomar decisiones políticas, o al menos que se sometiese a un mayor control a los judíos de la mano «mayor» que tenían en sus manos el gobierno de la aljama.

Por virtud de un privilegio del rey Jaime concedido a la aljama bilbilitana, veinte judíos debían hacerse cargo cada año de la administración y gestión de ésta ${ }^{11}$. Y, según atestiguan algunas denuncias presentadas en las primeras décadas del siglo XIV, todos ellos tendieron a reclutarse entre los integrantes de la mano «mayor». Por este motivo, comprensiblemente, entre los miembros de la

9 ACA, C, reg. 159 - 164, Zaragoza, 3-XII-1316. Referencia al pleito que se había seguido entre Mossé el Saje y Iucef Gemanet, judíos, de una parte, y algunos singulares de la mano inferior de los judíos de la aljama de Calatayud, de otra. Y reg. 619 - 144, Barcelona, 24-VI-1342. Referencia a una provisión real por la que se ordenaba que la aljama de Calatayud, o los judíos de la «mano mayor», no pudiesen aprobar ninguna ordenanza ni decidir el envío de embajadores a la Corte del rey sin la presencia y consentimiento de algunos judíos de la «mano menor». López Asensio afirma que entre los judíos de Calatayud existieron tres manos (mayor, menor y media) pero sin indicar ninguna referencia documental. Vid. su «Organización y gobierno de la aljama judía de Calatayud», en IV Encuentro de Estudios Bilbilitanos. Calatayud y Comarca (Calatayud 1997), 127-150, estudio poco riguroso, en el que se prescinde de aportar pruebas documentales.

${ }^{10}$ Carta de la infanta María, hija de Jaime II, a su hermano el infante Alfonso, fechada en Calatayud, 22-IX-1325, en que hace referencia a Abrahem Boco y Yucé del Sage, procuradores de los judíos «menudos» de Calatayud. Cf. F. BAER, Die Juden im christlichen Spanien. Aragonien und Navarra (Berlin 1929), doc. 181, págs. 241-242.

${ }^{11}$ Esta referencia a los «veinte» aparece en ACA, C, reg. 619 - 144, Barcelona, 24-VI-1342, además de en el documento citado en nota anterior. No sabemos qué relación tenían con los adelantados de la aljama, que en número de cuatro habían sido establecidos por Jaime I en la temprana fecha de 1229. Es probable que los referidos «veinte» constituyesen el Consejo de la Aljama. No es nuestra intención, sin embargo, entrar a analizar en detalle la historia institucional de la aljama bilbilitana, por tratarse de una tarea que merece que se le dedique otro trabajo monográfico, basado en la utilización de una masa documental más amplia. 
mano «menor» se tendió a considerar con creciente suspicacia sus actuaciones, lo que les movió en alguna ocasión a solicitar al rey que sometiese a juicio de residencia a estos oficiales, para comprobar si habían cometido irregularidades durante el desempeño de sus oficios, y, en caso de detectarlas, castigar a los culpables. Así procedieron, por ejemplo, en 1325 ante Jaime II, quien atendiendo su solicitud, comisionó a un juez de su casa, Domingo de Tarva, para que tomase cuentas a los veinte judíos administradores de la aljama que habían desempeñado el oficio durante el quinquenio precedente, e hiciese pesquisas sobre cómo habían llevado la administración de los negocios de la aljama durante ese período. Pero esta decisión no fue bien acogida entre los veinte que tenían a su cargo la administración de la aljama, los cuales recurrieron a todo tipo de maniobras para impedir que se llevase a efecto esta comisión, llegando incluso a propiciar la presentación de falsas acusaciones contra uno de los procuradores de los judíos «menudos», Abrahem Boco, para provocar su detención e impedirle así que siguiese adelante con su campaña de «acoso» contra ellos. En concreto, convencieron a la suegra de este judío para que presentase denuncia contra él por haberla herido cuando se encontraba amparada por una carta de seguro, y a raíz de ello el lugarteniente de baile procedió a encarcelarle, si bien consiguió escapar de la cárcel y refugiarse en las casas de la infanta María, hija del rey Jaime II, y viuda del infante Pedro de Castilla, que entonces residía en Calatayud. E inmediatamente después la propia infanta intercedió a favor de Abrahem Boco, escribiendo a su hermano, el infante Alfonso, lugarteniente del reino de Aragón, para solicitarle que ordenase que se le dejase en libertad, haciéndole saber que «según me han hecho entender los más de la judería, él demanda derecho y cosa que es vuestro servicio» ${ }^{12}$.

Los miembros de la mano «menor» no se conformaron, sin embargo, con este tipo de soluciones «a posteriori» para limitar el alcance de las actuaciones abusivas que, en contra de sus intereses como grupo, pudiesen cometer los miembros de la mano «mayor» que controlaban el aparato institucional de gobierno y administración de la aljama. Por el contrario, se esforzaron también por conseguir que se les garantizase una vía regular de participación en la gestión de los asuntos públicos, al menos de aquéllos que en mayor medida les pudiesen afectar. Y así, en concreto, sabemos que pusieron especial empeño en conseguir la aprobación por el rey de alguna medida que impidiese a los miembros de la mano «mayor» la aprobación de ordenanzas o el envío de embajadores a la Corte sin que estuviesen presentes a la hora de la toma de la decisión algunos representantes de la mano «menor», y manifestasen su aprobación.

${ }^{12}$ Vid. BAER, Die Juden... Aragonien, doc. 181, págs. 241-242.

Sefarad, vol. 67:2, julio-diciembre 2007, págs. 327-365. ISSN 0037-0894 
A comienzos de la década de 1340 tenemos constancia, en efecto, de que esta cuestión estuvo en el primer plano del calendario político de la aljama judía bilbilitana y dio lugar al desencadenamiento de fuertes tensiones en su seno. Según relación contenida en un documento de junio de $1342{ }^{13}$, hacía poco tiempo que varios judíos de Calatayud, «ministeriles et curritores», es decir dedicados al trabajo artesanal y a la correduría, que por costumbre nunca habían sido admitidos a participar en tareas de administración de la aljama, obtuvieron en la Corte de Pedro IV una real provisión por la que este monarca disponía que ni la aljama de Calatayud ni los judíos de la mano «mayor» pudiesen aprobar ninguna ordenanza ni decidir ningún envío de embajadores a la Curia del rey sin la presencia y consentimiento de algunos judíos de la mano «menor». El contenido de esta provisión no fue del agrado de los judíos dirigentes de la aljama bilbilitana que, por todos los medios a su alcance, debieron presionar al resto de miembros de la comunidad para tratar de impedir que se llevase a cumplimiento lo en ella dispuesto. $\mathrm{Y}$ en un primer momento lo consiguieron, pues cuando la provisión fue presentada en la sinagoga mayor de los judíos de Calatayud, estando congregada la aljama al modo acostumbrado, tanto la aljama como los judíos de la mano «menor» hicieron renuncia expresa a servirse de la misma, dejando constancia de ello mediante el otorgamiento de un instrumento público suscrito por notario.

No todos los miembros de la mano «menor» debieron estar de acuerdo, sin embargo, con esta forma de proceder, puesto que poco después, a instancia de algunos judíos que se identificaron a sí mismos como procuradores de dicha mano, entre los que había carniceros, tejedores, corredores y menestrales, el escribano real Jimeno Garcés de Fillesa ordenó de nuevo bajo cierta pena a la aljama y a los judíos de la mano «mayor» que no aprobasen ordenanzas ni designasen legaciones sin estar presentes representantes de la mano «menor». Y estos mismos procuradores consiguieron que el rey volviese a confirmar la provisión que había dado con anterioridad, al uso de la cual se había renunciado formalmente en asamblea de la aljama celebrada en la sinagoga mayor.

Parece seguro, por tanto, que los judíos de la mano «mayor», en su afán por impedir que se les obligase a compartir con representantes de la mano menor la responsabilidad de la toma de decisiones políticas en la aljama, trataron de manipular a aquellos miembros de esta última mano sobre los que podían ejercer mayor influencia a fin de neutralizar la maniobras del sector de la misma que se estaba movilizando para acabar con el monopolio en el ejercicio del poder del que venían disfrutando aquéllos. Y mediante esta manipulación conseguirían

\footnotetext{
${ }^{13}$ ACA, C, reg. 619 - 144, Barcelona, 24-VI-1342. Comisión al baile de Calatayud.
} 
que la asamblea de la aljama renunciase formalmente a hacer uso de la provisión que se había obtenido en la Corte. La tenacidad de sus opositores impidió, sin embargo, que alcanzasen plenamente su objetivo, y por ello debieron redoblar sus esfuerzos ante el rey, para tratar de convencerle de la necesidad de revocar las concesiones que había hecho a los representantes de la mano menor. A este efecto recurrieron al argumento de que los individuos que formaban parte de esta mano eran personas ignorantes y que perturbaban con frecuencia el buen estado y tranquilidad de la aljama ${ }^{14}$, e incluso sugirieron que lo razonable era que el gobierno y la administración de ésta estuviese en manos de los que más contribuían a su sostenimiento financiero mediante los impuestos que pagaban ${ }^{15}$.

No sabemos cómo se resolvió finalmente este litigio, puesto que Pedro IV se limitó a delegar en manos del baile de Calatayud la tarea de solucionarlo, aconsejándole que procediese «prout utilitate dicte aljame videretis expedire» ${ }^{16}$. Pero, en cualquier caso, creemos que las noticias que hemos aportado proporcionan buena prueba de la intensidad del enfrentamiento que a comienzos de la década de 1340 se había desencadenado en el seno de la comunidad judía bilbilitana entre un reducido grupo de judíos acaudalados, que presumimos que estaría constituido preferentemente por financieros, mercaderes y otros profesionales liberales como, por ejemplo, médicos, que se esforzaba por consolidarse como cerrada oligarquía, y otro sector constituido por corredores, artesanos, e incluso carniceros, con posición económica más modesta, que se veía sistemáticamente desplazado del principal órgano de gobierno de su comunidad, pero que no aceptaba de buen grado esta exclusión, y demostró tener suficiente capacidad de movilización como para desafiar a los primeros. A pesar de ello tampoco se ha de exagerar, sin embargo, a la hora de caracterizar a los judíos de la mano «mayor» como cerrado grupo oligárquico, pues no debemos olvidar que, según se reconoce en los documentos aludidos, el gobierno de la aljama judía bilbilitana estaba en manos de una veintena de personas, que presumimos que se renovaban con relativa frecuencia, aunque este extremo habría que comprobarlo en futuras investigaciones centradas en la reconstrucción de la historia institucional de dicha aljama.

Por otra parte, tenemos constancia de que al margen de repartirse, en función de su posición socioeconómica y grado de influencia política en dos grandes

${ }^{14}$ En concreto, acusaron a los judíos de la mano menor de que «propter ignorantiam et insuficienciam quibus subiacent turbant frequenter bonum et tranquillum statum aljame».

${ }^{15}$ La fórmula empleada para expresar la idea es la siguiente: «In regimine et administratione hac sint illi judei dicte aljame iuxta dicta privilegia et consuetudinem merito eligendi quos opportet varia onera peytarum et aliarum exactionum regalium ac expensarum commodi et sustentationis dicte aljame necessario sustinere».

${ }^{16}$ ACA, C, reg. 619 - 144, Barcelona, 24-VI-1342. Comisión al baile de Calatayud. 
«manos», los judíos bilbilitanos también dieron vida a otras agrupaciones de carácter asociativo, aunque de momento sabemos poco sobre el papel que éstas desempeñaron en la vida social de la comunidad, o sobre los criterios de pertenencia a las mismas. Nos referimos a las cofradías ${ }^{17}$, entre las cuales cabe destacar la llamada «del Midrás», que estaba bien implantada a comienzos del siglo XIV, cuando algunos indicios nos hacen presumir que debió tener una intensa intervención en la vida política local, o más en concreto en la de la comunidad judía. Al menos así interpretamos la información que proporciona un documento del año 1316, según la cual a algunos judíos de Calatayud, «ex illis qui vocantur de Midras», se les había condenado a pagar 6.000 sueldos jaqueses como castigo "por algunos excesos que habían cometido» ${ }^{18}$.

Como otras cofradías de judíos, la «del Midrás» nos consta que estuvo dotada con un patrimonio de bienes raíces que en parte se constituyó mediante operaciones de compra, como la realizada por Jacob Abenhalez hacia 1360 de varias casas, viñas y tierras ${ }^{19}$. Presumiblemente este patrimonio se explotaría con el fin de destinar su producto a la financiación de las obras piadosas y de beneficencia que tenía a su cargo la cofradía, pero de momento no hemos encontrado en la documentación consultada información que permita conocer con más detalle este aspecto. Y con semejantes problemas de falta de información tropezamos al abordar el estudio de otras cofradías de judíos que tenemos noticia que existieron en Calatayud a lo largo del siglo XIV, como la de «La Almosna», llamada en hebreo «El Haquedes» (Hecdeš) ${ }^{20}$, o la de «Sombre Holim» (o «de cuidar enfermos»), que primero se llamó «de los tejedores», la cual tuvo su sede en la sinagoga llamada «menor» ${ }^{21}$.

${ }^{17}$ Un interesante estudio sobre el papel de las cofradías en una comunidad judía aragonesa en A. Blasco MartíneZ, «Instituciones sociorreligiosas judías de Zaragoza (ss. XIV-XV). Sinagogas, Cofradías, Hospitales», Sef 49 (1989), 227-236; y 50 (1990), 3-46 y 265-288.

18 ACA, C, reg. 159 - 120v, Zaragoza, 23-XI-1316. Comisión a Pedro Garcés de Usa, baile de Calatayud, para que resuelva los conflictos que se estaban planteando con motivo del reparto de dicha cantidad entre los afectados.

${ }^{19}$ Información respecto a esta operación en ACA, C, reg. 699 - 210v, Zaragoza, 13-III-1360. Comisión a García Muñoz de Pamplona, jurisperito de Calatayud, para conocer en el pleito que se seguía entre el procurador de los cofrades de la cofradía llamada «Elemosine del Midras», de una parte, y la aljama de judíos de Calatayud y algunos singulares de dicha aljama, entre los cuales se cita a Salamón Abenhalez y su mujer Rica, de otra parte, sobre ciertas casas, viñas y tierras compradas por Jacob Abenhalez «ad opus dicte confratrie».

${ }^{20}$ Referencia a esta cofradía en un documento de 1381 en ACA, C, reg. 823 - 58.

${ }^{21}$ Marín Padilla, «Notas sobre la familia Lupiel de Calatayud (1482-1488)», pág. 260. Todavía a principios del siglo Xv la sinagoga donde tenía su sede la cofradía se seguía llamando «de los Texidores». Así consta en la merced que en 1421 hizo la reina María, esposa de Alfonso V, 
2. El GRUPO PRIVILEGIADO DE LOS «JUDÍOS FRANCOS»: DATOS PARA SU IDENTIFICACIÓN

En la cúspide de la escala jerárquica de la comunidad judía bilbilitana se encontraba un reducido grupo de familias que gozaban del privilegio de la exención de impuestos, a los miembros de las cuales se conocía por esta razón con el nombre de «judíos francos». Asunción Blasco identifica a cinco familias de judíos francos en el reino de Aragón, de las cuales dos estaban establecidas en la ciudad de Zaragoza, (Alazar y Caballería), y tres en la de Calatayud (Costantiní, Abentilca y Abendahuet o Abendavid) ${ }^{22}$. Según esta autora todas ellas tenían en común el ser vasallas de la Orden del Hospital de San Juan de Jerusalén, y por esta razón sus miembros se diferenciaban de otros judíos que también disfrutaban de la exención de impuestos por estar al servicio de la casa real y haber recibido merced de exención tributaria, a título temporal o de forma vitalicia, en recompensa por sus servicios ${ }^{23}$.

Sea como fuere, lo cierto es que los judíos francos en Calatayud debieron llegar a constituir un grupo relativamente numeroso a finales del siglo XIV, que integraría a otras muchas familias aparte de las tres arriba mencionadas. Así lo sugiere, al menos, el hecho de que el rey en 1388 les ordenase que, para tratar ciertos asuntos en los que necesitaba su colaboración, le enviasen dos procuradores ${ }^{24}$. Por este motivo resulta comprensible que las autoridades de la aljama se esforzasen por limitar al máximo el alcance de sus exenciones tributarias, y tratasen de obligarles a contribuir al menos en el pago de determinados impuestos, a lo cual ellos se resistieron, generalmente con éxito. Así ocurrió, por ejemplo, en 1316, cuando, según informaron al rey representantes de la aljama, ésta había incurrido en elevados gastos para defenderse de las acusaciones de práctica de usura presentadas contra judíos bilbilitanos, y para atender a otros negocios que eran «útiles y necesarios y comunes a los judíos pecheros y francos». Por

a Diego Gómez de Castro, clérigo de su capilla, de «illas duas domos sive sinagogas sitas in judaría civitatis Calataiubii», la una llamada de «las carneceries», y la otra de «los texidores»; vid. ACA, C, reg. 3119-123. Por su parte Magdalena Nom de Déu, «Sinagogas, madrazas y oratorios», págs. 120-121, sostiene que la sinagoga llamada «Madraza de los Tejedores» era propiedad de la cofradía de los tejedores judíos de Calatayud.

${ }^{22}$ A. Blasco Martínez, «Los judíos del reino de Aragón: Balance de los estudios realizados y perspectivas», Ier. Col·loqui d'Història dels jueus a la Corona d’Aragó (Lleida 1991), pág. 63.

${ }^{23}$ Ibid., pág. 76. Según información oral proporcionada por J. Castaño, esta autora, en un congreso celebrado en Gerona en 2003, cuyas actas aún no se han publicado, puntualizó que las familias Constantiní y Abendahuet (Abendavid) no eran vasallas de la Orden del Hospital.

${ }^{24}$ ACA, C, reg. 1946 - 64, Zaragoza, 30-V-1388.

SeFARAD, vol. 67:2, julio-diciembre 2007, págs. 327-365. ISSN 0037-0894 
ello, los dirigentes de la aljama entendían que también los judíos francos debían contribuir a su financiación, pero éstos se habían negado a hacerlo, amparándose en sus privilegios. Y de ahí que los primeros recurriesen al rey para solicitarle que obligase a estos últimos a pagar como el resto de sus correligionarios ${ }^{25}$. En aquella ocasión el monarca encargó al baile de Calatayud que entendiese en este asunto, pero no sabemos cómo se resolvió la disputa. En cualquier caso, ésta volvió a replantearse en parecidos términos en otras ocasiones a lo largo del siglo, mientras que los reyes tomaban medidas contradictorias al respecto, que muy poco contribuyeron a resolver el problema. Así, por ejemplo, a comienzos del año 1360, a petición de cierto sector de la población judía de Calatayud, la cancillería regia expidió una carta por la que obligaba a los judíos francos de esta ciudad a contribuir en la financiación de determinados gastos de la aljama, de los llamados «vecinales», es decir, los que no estaban relacionados con el pago de impuestos a la monarquía ${ }^{26}$. Pero inmediatamente los judíos francos afectados recurrieron al rey Pedro IV, recordándole que, en virtud de privilegios otorgados por él y por sus antecesores, ellos estaban exentos de contribuir con cualesquier aljama en todas las pechas y demás exacciones, tanto reales como vecinales. Y consiguieron que éste atendiese sus ruegos, puesto que, aunque no revocó la carta que hacía poco tiempo había expedido su cancillería, ordenó al baile de Calatayud que, a pesar de lo que se dispusiese en ella, continuase guardando a los judíos francos los privilegios adquiridos, lo que en la práctica equivalía a dejar sin efecto la referida carta ${ }^{27}$. Pero años más tarde volvemos a constatar que continuaba planteado el problema, puesto que la aljama volvió a exigir que los judíos francos contribuyesen en el pago de las cantidades gastadas en la realización de obras de fortificación del barrio judío, y del sueldo que se debía abonar al infante Juan por su condición de protector de los judíos, mientras que aquéllos de nuevo se negaron a hacerlo ${ }^{28}$.

En cualquier caso, por otras referencias documentales sabemos que los judíos francos de Calatayud no lograron escapar plenamente al pago de todo tipo de impuestos, sino que al menos se vieron obligados a contribuir en algunas

${ }^{25}$ ACA, C, reg. 160 - 175 Tarragona, 28-V-1316. Carta dirigida al baile de Calatayud.

${ }^{26}$ La expresión que se utiliza en el documento es «in aliquibus expensis vicinalibus aljame». La carta en cuestión fue expedida en Zaragoza, 2-III-1360.

27 ACA, C, reg. 1171 - 13, Pedrola, 13-V-1360.

${ }^{28}$ BAER, Die Juden... Aragonien, doc. 283, pág. 399. Orden de Pedro IV de 22-VI-1367. En concreto, los gastos en los que la aljama quiere obligar a contribuir a los judíos francos son los ocasionados «in operibus murorum et vallorum et in retinentia castri de la juderia et in salario quod ipsa aljama annuatim prestare tenetur inclito infanti...protectori aliamarum judeorum totius terre nostre». 
derramas realizadas en el seno del propio grupo para atender determinados gastos que se le originaban a éste como colectivo, por ejemplo a raíz del envío de embajadas ante el rey para defensa de sus intereses. Así nos lo confirma en concreto la denuncia presentada ante Pedro IV en 1360 por Maestre Bayel, judío franco y médico de profesión, quien se consideró agraviado porque tanto él como su madre eran tasados en muy superior cuantía de la que les correspondía por sus «facultades» en las derramas en las que contribuían junto con los demás judíos francos de la villa («in missionibus et aliis pro quibus contribuere habent cum aliis judeis franchis dicte ville») ${ }^{29}$.

Para unos pocos judíos bilbilitanos, por otra parte, el privilegio de exención de impuestos se vio ampliado por otro, también muy valioso y codiciable, que les libraba de la incómoda obligación de alojar como huéspedes a cristianos en sus casas. Sabemos que en 1367 fueron premiados con esta merced por el rey Pedro IV dos individuos pertenecientes a dos conocidas familias de judíos francos, Salamón Abendahuet y Tadroç Abentilca, quienes, según reza el privilegio de concesión, la recibieron en compensación por haber sido destruidas sus casas durante la invasión castellana, y por los muchos servicios que habían prestado al tesorero real ${ }^{30}$.

Los judíos francos de Calatayud sobre los que mayor cantidad de información disponemos relativa a sus trayectorias profesionales fueron, en efecto, individuos que desarrollaron una intensa actividad en la recaudación de impuestos por cuenta de los reyes de Aragón, a los que prestaron con frecuencia auxilio financiero, que éstos les compensaron mediante la concesión de diversas mercedes y privilegios. Valiosos ejemplos ilustrativos en este sentido nos proporciona la familia Abendahuet o Abenalahud (Abendavid). A ella pertenecía Açach Abenalahud, quien, como indicaremos más adelante, prestó importantes servicios financieros a la infanta María, hija de Jaime II, que movieron a ésta a solicitar a su padre que le compensase mediante la concesión de una serie de importantes privilegios, a lo que, al menos en parte, éste accedió, pues en 1326 concedió que contribuyese a la pecha y demás impuestos repartidos por la aljama de Catalayud conforme a la tasa que fijase el baile, y no los tasadores nombrados por la aljama ${ }^{31}$. Pero también el propio Jaime II se benefició de los

\footnotetext{
${ }^{29}$ ACA, C, reg. $699-194 \mathrm{v}$, Borja, 22-III-1360. Comisión a Miguel Pérez de Terrer, jurisperito de Calatayud.

30 ACA, C, reg. 913 - 224, Zaragoza, 26-IV-1367. Cf. BAER, Die Juden... Aragonien, doc. 277, pág. 393.

31 Vid. J. RÉGNÉ, History of the Jews in Aragon. Regesta and Documents 1213-1327 (Jerusalem 1978), pág. 621, doc. 3399. Remite a ACA, C, reg. 228 - 134v, Barcelona, 24-VI-1326.
} 
servicios financieros prestados por este judío y otros miembros de su familia, por los que les compensó mediante la concesión de sustanciosos privilegios. Así, en primer lugar, en 1312 dispuso que tanto él como sus hermanos Ismael y Mossé, y su padre Iucef Abenalahud, no pechasen con la aljama de judíos de Calatayud hasta recibir plena compensación por los $4.000 \mathrm{~s}$. j. que le habían prestado ${ }^{32}$. Más adelante, en 1320, ordenó que Açach y Mossé Abenalahud, sus hijos, y los hijos de Ismael Abenalahud, su hermano, que para entonces ya debía haber muerto, quedasen apartados del resto de familias de la aljama judía bilbilitana durante cuatro años, a efectos de contribuir en el pago de impuestos vecinales, es decir de los que se cargaban para cubrir los gastos a los que tenía que hacer frente la aljama, y no para atender las demandas fiscales de la monarquía. Más en concreto dispuso que, en este intervalo de cuatro años, siempre que la aljama realizase derramas de carácter «vecinal», los referidos miembros de la familia Abenalahud en conjunto abonasen una décima parte del total repartido, corriendo a cargo de los demás contribuyentes de la aljama el pago de las nueve partes restantes ${ }^{33}$. A primera vista, por tanto, cuesta comprender dónde podía residir el carácter privilegiado del trato dispensado a esta familia, por cuanto quedaba obligada a aportar una proporción bastante importante del total de la recaudación de impuestos de la aljama en su conjunto. No queda sino pensar que la riqueza acumulada entonces por los Abenalahud debía ser enorme, y que, al fijarse su contribución a las derramas «vecinales» en una décima parte del total repartido, se les estaba exigiendo una cantidad previsiblemente inferior a la que les correspondería abonar de aplicarse los criterios de proporcionalidad asumidos por el aparato fiscal de la aljama, a los que aluden los documentos cuando hablan de repartos «por sueldo y libra». De otro modo no habría tenido sentido que aceptasen este régimen de contribución, que además les comprometía por cuatro años, durante los que podían sufrir mermas significativas tanto su patrimonio como sus fuentes de ingreso, que justificasen una fuerte reducción de su base imponible.

No hemos podido entrar a determinar cómo evolucionó la situación fiscal de los descendientes de estos judíos de apellido Abenalahud a partir del reinado de Jaime II. En la documentación de la segunda mitad del siglo XIV este apellido deja de aparecer, para adoptar la forma de Abendahuet, otra variante de Abendavid. Entre los vecinos de Calatayud portadores de este apellido hay que destacar en esta época a Salamón Abendahuet, judío franco que tuvo cargo por el rey Pedro IV de re-

32 RéGNÉ, History, pág. 546, doc. 2950 (ACA, C, reg. 209 - 202, Gerona, 1-IX-1312).

${ }_{33}$ BAER, Die Juden... Aragonien, doc. 174. Privilegio de Jaime II otorgado en Calatayud, 29-VII-1320. 
caudar muy diversas rentas, tales como las demandas debidas a la monarquía por la Comunidad de aldeas de Calatayud en $1366^{34}$, o el peaje y otros derechos debidos al rey en la villa de Aranda en $1369{ }^{35}$. En 1380 este monarca le hizo merced de 2.000 s. j. en remuneración por diversos trabajos que había realizado en su servicio ${ }^{36}, \mathrm{y}$ al año siguiente encargó por carta a su hijo primogénito, el lugarteniente Juan, que no consintiese que fuese oprimido o vejado por ningún oficial, recordándole que había trabajado «continuamente en los negocios de nuestra Corte y Tesorería, proporcionándonos provecho» ${ }^{37}$. Y ciertamente el infante Juan atendió al pie de la letra los consejos de su padre, puesto que años después, cuando le sucedió en el trono, continuó mostrando una actitud de decidido apoyo a este judío franco bilbilitano, como bien lo pone de manifiesto la carta que en 1392 dirigió al gobernador del reino de Aragón, expresándole su deseo de que, en atención a los «agradables servicios» que había prestado al rey su padre, y le continuaba prestando a él, tanto él como sus hijos fuesen bien tratados por los oficiales y favorecidos en la justicia ${ }^{38}$.

Los hijos de Salamón Abendahuet dieron continuidad, en efecto, a la trayectoria profesional de su padre de servicio a los reyes de Aragón en asuntos financieros y fiscales. Así, su hijo Iucef Abendahuet tuvo a su cargo la recaudación, entre otras rentas, del portazgo de Calatayud ${ }^{39}$, y de la «quema», impuesto que incidía sobre los flujos comerciales entre la Corona de Castilla y el reino de Aragón ${ }^{40}$. Y sus servicios a la monarquía también fueron premiados con

${ }^{34}$ Vid. ACA, Maestre Racional [= MR], 646 - 165v. Finiquito expedido en Zaragoza, 18-III1372, en favor de Salamón Abendahuet, judío de Calatayud, a quien había encomendado el rey por carta de Zaragoza, 1-VI-1366, que recibiese de los vecinos de las aldeas de Calatayud 45.000 s. j. que debían pagar para San Miguel por la demanda que Pedro Jordán de Urriés, mayordomo del rey, les había efectuado en nombre del rey antes de la ocupación de Calatayud por el rey de Castilla.

${ }^{35}$ ACA, MR, 650 - 87v. Se hace constar que Salamón de Abendahuet, judío de Calatayud, fue designado por carta del rey de Zaragoza, 8-VI-1366, como recaudador del peaje y otros derechos del rey en Aranda, y usó de dicha comisión durante 3 años y 2 meses, entre septiembre de 1367 y el 30 de noviembre de 1370 .

${ }^{36}$ ACA, C, reg. 1100 - 151, Zaragoza, 18-XII-1380.

${ }^{37}$ ACA, C, reg. 824 - 32, Zaragoza, 25-XI-1381. Carta de Pedro IV a su primogénito, el infante Juan.

${ }^{38}$ ACA, C, reg. 1881 - 88v, Valencia, 16-XII-1392. Carta del rey al gobernador del reino de Aragón.

39 Vid. ACA, C, reg. 2344 - 119, Barcelona, 28-IX-1396. Carta de María de Luna al baile de Calatayud y al merino de Zaragoza para que ordenen a Iucef Abendahuet que acuda a la Curia a informar sobre ciertos asuntos relacionados con el producto del peaje de Calatayud, que éste recaudó durante algún tiempo.

40 Noticia en ACA, MR, 258. Se informa que Juan Don Sancho vendió el derecho de la «quema» de Aragón a Iucef Abendahuet por 3 años por carta de arrendamiento de 10-XI-1387. 
diversas mercedes, como la que le hizo el rey Juan I en 1386, asignándole de forma graciosa $300 \mathrm{~s}$. j. sobre el dinero proveniente de las últimas demandas efectuadas por el baile general de Aragón a las aldeas de Calatayud, lo que invita a presumir que él habría tenido parte importante en su negociación con los representantes de las aldeas ${ }^{41}$.

Al analizar la trayectoria de la familia Abendahuet en la segunda mitad del siglo XIV un hecho que llama, bastante la atención es que sus miembros gozaron de la confianza de los reyes de Aragón no sólo en negocios relativos a finanzas y recaudación de impuestos, sino que también tuvieron intervención en asuntos de carácter decididamente político, y que sólo afectaban a la población cristiana. Así, en primer lugar, durante el reinado de Pedro IV, Salamón Abendahuet debió intervenir de alguna manera en la resolución del conflicto de índole jurisdiccional que en torno al año 1373 enfrentaba a la ciudad de Calatayud con las aldeas de su Comunidad, pues en varios documentos expedidos por la cancillería regia ese año se reconocía que los vecinos de la ciudad le profesaban un odio visceral, porque le consideraban responsable de que las aldeas hubiesen obtenido en la Curia ciertas provisiones y privilegios que cercenaban las facultades jurisdiccionales de Calatayud. Ciertamente el rey se apresuró a desmentir estas acusaciones, insistiendo en que las provisiones se habían obtenido por vía de justicia, de modo que no había habido lugar para trato ni mediación alguna ${ }^{42}$. Pero cuesta creer que la animadversión hacia Salamón Abendahuet entre los vecinos de Calatayud no tuviese algún tipo de fundamento en las actuaciones de éste. Y no deja de resultar sorprendente que un judío pudiese influir de forma tan decisiva en la Corte de los reyes de Aragón sobre la toma de decisiones en asuntos que afectaban de forma prácticamente exclusiva a la población cristiana.

Durante estos años hubo, sin embargo, un tiempo en que no circularon mercancías entre Aragón y Navarra, y por ello Iucef presentó demanda contra Juan Don Sancho, que finalmente accedió a compensarle con $2.000 \mathrm{~s}$. j. por las mermas que por este motivo hubo en la recaudación del impuesto. Sobre el impuesto de la «quema» vid. mi «La "quema". Trayectoria histórica de un impuesto sobre los flujos comerciales entre las coronas de Castilla y Aragón durante los siglos XIV y XV», AEM 30:1 (2000), 91-156.

${ }^{41}$ ACA, C, reg. 1292 - 15, Barcelona, 25-VI-1386.

42 ACA, C, reg. 766 - 26 y 27v, Barcelona, 12-I-1373. Cartas del rey a la ciudad de Calatayud, al baile general de Aragón, y al justicia de Aragón, para que no se cause ningún daño a Salamón Abendahuet, que es servidor del rey. Y reg. 765 - 186, Barcelona, 12-I-1373, carta a Florencio Pérez de Pamplona, García Muñoz de Pamplona, Íñigo Navarro y Andrés Gómez, ciudadanos de Calatayud, ordenándoles que garanticen a Salamón Abendahuet poder circular libremente por esta ciudad, pues había denunciado que por el mucho odio que le tenían en ella no se atrevía a salir públicamente como antes solía. 
En cualquier caso no fue en 1373 la única ocasión en que Salamón Abendahuet se vio involucrado en la negociación de asuntos políticos que afectaban a la Comunidad de aldeas de Calatayud. De nuevo en 1390 nos consta que el rey de Aragón recurrió a él para que acudiese a parlamentar en su nombre con los oficiales de dicha Comunidad, según testimonia una carta que les dirigió a estos últimos desde Zaragoza en abril de 1391, en la que les manifestaba su deseo de que durante su estancia en Aragón se resolviesen definitivamente ciertas diferencias que mantenían con los vecinos de las aldeas, para lo cual les enviaba, informado de su intención, al judío Salamón Abendahuet ${ }^{43}$, al cual precisamente hacía pocos meses había convocado para que acudiese a la Corte, con el argumento de que le necesitaba «por asuntos tocantes a honra y provecho nuestro» ${ }^{44}$. Si tales asuntos tenían algo que ver con los problemas planteados en las aldeas de Calatayud no lo sabemos con seguridad. Pero es sintomático que poco después de haber reclamado su presencia en la Corte, el rey de Aragón enviase a este judío con instrucciones para tratar con los oficiales de la Comunidad de dichas aldeas. En cualquier caso, como quiera que fuese, consideramos relevante el hecho de que el monarca aragonés recurriese a un judío para negociar en su nombre con oficiales cristianos, que además eran representantes de una población campesina en la que estaban bastante arraigados los sentimientos antijudíos.

Esta forma un tanto sorprendente de proceder puede en parte explicarse si tenemos en cuenta que Salamón Abendahuet acumulaba una larga experiencia de trato con los oficiales de la Comunidad de aldeas de Calatayud por motivos relacionados con el cobro de impuestos, pues al margen de que en algunos ejercicios tuvo a su cargo la recaudación de los mismos en dicho ámbito, en otras ocasiones nos consta que actuó como negociador en nombre del rey con los representantes de dichas aldeas para lograr su consentimiento al pago de determinados impuestos, o a su cesión a la hacienda regia. Así, por ejemplo, tenemos noticia de que el mercader y financiero zaragozano Juan Don Sancho libró en una ocasión 1.000 florines de oro de Aragón a Salamón Abendahuet para que éste a su vez procediese a librarlos a las personas «que habían trabajado en los fechos de las primicias que los de la Comunidad de Calatayud otorgaron graciosamente al rey Juan» ${ }^{45}$,

${ }^{43}$ ACA, C, reg. 1959 - 178v, Zaragoza, 15-IV-1391.

${ }^{44}$ ACA, C, reg. 1959 - 147, Zaragoza, 28-XII-1390.

45 Vid. ACA, C, reg. 2154 - 102, Valencia, 7-XII-1407. Carta dirigida a Salamón Abendahuet, judío habitante en Calatayud, hijo de Iucef Abendahuet, y nieto de Salamón Abendahuet, sobre una reclamación presentada por Juan Don Sancho, mercader de Zaragoza, que había mostrado un instrumento público, fechado en Calatayud, 29-VII-1394, en el que su abuelo Salamón Abendahuet se obligaba a librar a Juan Don Sancho «ápocas» de aquellas personas a quien él decía que había librado los 1.000 florines de oro de Aragón, que Juan le había librado a él para satisfacer a las personas que habían trabajado en los fechos de las primicias que los de la Comunidad de Calatayud 
circunstancia que invita a presumir que este judío había tenido un papel destacado en dichas negociaciones.

Pero, en cualquier caso, la impresión de que los Abendahuet participaron en la vida política bilbilitana de una forma mucho más directa de lo que era habitual entre los miembros de la comunidad judía queda reforzada por algunas otras constataciones. Así, consideramos bastante sintomático el hecho de que en 1388, entre la docena de vecinos de Calatayud a los que el justicia encerró en prisión, inculpados de haber quebrantado la paz impuesta por la sentencia arbitral pronunciada por el infante Juan en 1378, había sólo un judío, precisamente Jucef Abendahuet ${ }^{46}$.

Aparte de los indicios a los que hemos hecho hasta ahora referencia, algunos otros nos confirman que la de los Abendahuet fue una de las más privilegiadas entre todas las familias judías del reino de Aragón durante la segunda mitad del siglo XIV y las primeras décadas del siglo $\mathrm{XV}$ y que su radio de influencia se extendía mucho más allá de la ciudad de Calatayud. Así, hay que destacar el hecho de que disfrutaba de un curioso privilegio que le garantizaba la percepción a perpetuidad de una renta de dos libras de cordero sobre la lezda de la carnicería de los judíos de Zaragoza, que le reportaba cada año en torno a $210 \mathrm{~s}$. $\mathrm{j}{ }^{47}$. Desconocemos cuál era el origen de este singular privilegio, pero el hecho de que disfrutase del mismo nos prueba que la familia mantenía fuertes vínculos con la principal comunidad judía del reino de Aragón, la de Zaragoza, aunque no tenemos noticia de que alguno de sus miembros llegase a residir en ella. Por el contrario sí sabemos que uno de los hijos de Salamón Abendahuet, de nombre Todroç, trasladó su residencia a la ciudad de Teruel, donde se le continuó reconociendo su condición de judío franco.

Si admitimos que todos los judíos identificados en las fuentes con los apellidos Abenalahud, Abendahuet y sus variantes formaban parte de una misma

otorgaron graciosamente al rey Juan. Juan Don Sancho denunciaba que Salamón Abendahuet no había cumplido con su compromiso, por lo que ahora pedía cuentas a su nieto como su heredero.

${ }^{46}$ ACA, C, reg. 1955 - 50, Zaragoza, 15-VII-1388.

${ }^{47}$ Noticia de este privilegio en ACA, C, reg. 2159 - 32, Barcelona, 28-VI-1408. Todroç Abendahuet, judío franco de la aljama de Teruel, hijo de Salamón Abendahuet, judío franco de Calatayud, y los hijos de Samuel Abendahuet, hijo del dicho Salamón, y los hijos de Iucef Abendahuet, hijo también del dicho Salamón, todos éstos vecinos de Calatayud, habían informado que tenían privilegio para cobrar en la lezda de la carnicería de los judíos de Zaragoza «duas libras mutonis qualibet die in perpetuum». En satisfacción de estas dos libras solían recibir anualmente del dinero de la lezda 210 s. j., que les abonaba el merino de Zaragoza, pero ahora éste había dejado de pagárselos. Ya en 1291 Jaime II confirmó a miembros de la familia Abendahuet este privilegio que había sido concedido a sus antepasados por el rey Pedro. Vid. RÉGNÉ, History, pág. 450, doc. 2406, que remite a ACA, C, reg. 192 - 41, Calatayud, 31-X-1291. 
familia, la de los Abendavid, deberemos concluir, no obstante, que el grado de franqueza de ésta experimentó cierta evolución a lo largo del siglo XIV, puesto que sólo era parcial en sus primeras décadas, según hemos podido demostrar. Es una cuestión que habrá que clarificar en el futuro, para lo cual será preciso reconstruir con mayor precisión el árbol genealógico de esta familia, determinando con exactitud la relación de parentesco existente entre los diversos individuos que aparecen en la documentación con este apellido, en sus diversas variantes, a lo largo de dicho siglo.

Sobre las otras familias de judíos francos de Calatayud hemos logrado reunir bastantes menos noticias que sobre los Abendahuet, aunque las pocas de las que por el momento disponemos nos ofrecen una imagen de ellas que coincide a grandes rasgos con la de estos últimos. Así, por ejemplo, en el caso de los Abentilca constatamos que mantuvieron fuertes vínculos con la comunidad judía de Zaragoza, donde poseían una tabla de carnicería por virtud de un privilegio concedido por el rey Pedro II en el año 1205, la cual era servida por un carnicero y un ayudante o «escorchador», que cortaban en ella la carne y respondían del pago a la familia de la lezda y otros derechos ${ }^{48}$.

Al hablar de los Abenalahud en tiempos de Jaime II hemos podido comprobar cómo la franqueza concedida a determinados judíos podía tener sólo carácter parcial. Los ejemplos que proporciona la documentación que nos lo confirman son, por otra parte, relativamente numerosos, y conviene tenerlos en cuenta para hacerse idea de la diversidad que caracterizaba al grupo de los judíos francos, en el que coexistían individuos con grados de exención muy diferentes entre sí. A este respecto cabe recordar en primer lugar que la infanta María, hija de Jaime II y viuda del infante Pedro de Castilla, durante los años

${ }^{48}$ Vid. A. Blasco Martínez, La judería de Zaragoza en el siglo XIV (Zaragoza 1988), pág. 217 (doc. 3). Contrato notarial fechado en Zaragoza, 1-I-1361. Salomón Alazar, judío de Zaragoza, como procurador de don Todroç Abentilca, judío de Calatayud, provee de carnicero, ayudante y escorchador a la tienda que éste posee en la carnicería de judíos de Zaragoza. Consta, no obstante, que durante la ocupación de Calatayud por las tropas castellanas de Pedro I, el monarca aragonés confiscó todos los bienes de los vecinos de Calatayud, tanto cristianos como judíos. Entre dichos bienes confiscados estuvo esta tabla que Todroç Abentilca poseía en la carnicería de la judería de Zaragoza, de la cual el rey hizo merced poco después a un judío zaragozano llamado Iucef Arrut. A la medida se opuso, sin embargo, el judío zaragozano Salamón de la Caballería, alegando que Todroç Abentilca le adeudaba por instrumento público judaico $3.000 \mathrm{~s}$. j., por lo cual el rey no podía haber hecho merced de la dicha tabla de carnicería en perjuicio suyo, como acreedor que era a los bienes del dicho Todroç Abentilca. En respuesta a esta alegación Pedro IV ordenó que del precio que se obtuviese de dicha tabla («de pretio dicte lezde habito seu habendo») se diese satisfacción a Salamón de la Caballería de la cantidad que le adeudaba Todroç Abentilca. Vid. ACA, C, reg. 1202 - 181v, Zaragoza, 10-X-1364.

Sefarad, vol. 67:2, julio-diciembre 2007, págs. 327-365. ISSN 0037-0894 
de su estancia en Calatayud, tras la muerte de su marido en $1319^{49}$, recurrió en varias ocasiones ante su padre para solicitarle la concesión de privilegios a judíos bilbilitanos que le habían prestado señalados servicios, que, no obstante, no conllevaban la consecución de la franqueza plena. Así, en 1325 consiguió que Jaime II concediese la exención de la obligación de contribuir en todos los impuestos, con excepción de la pecha y la cena, a Benveniste Abenpesat y a su hermana Jamila, que vivía con él ${ }^{50}$. Al año siguiente le volvió a pedir que, para premiar a maestre Salamón por los servicios que les había prestado a ella y a su hija doña Blanca como médico, le quitase su pecha, que ascendía en aquellos momentos a dos sueldos y dos dineros en cada «arca» o derrama, o al menos la redujese a la mitad ${ }^{51}$. Y también en 1326 le solicitó la concesión de una serie de privilegios a Açach Abenalahud, quien, como hemos visto, con anterioridad ya había recibido otros de exención parcial del propio rey, en atención a los servicios de carácter financiero que le estaba prestando, adelantándole importantes cantidades de dinero para su sostenimiento. En concreto pidió que, para compensarle por las pérdidas en las que como consecuencia de estos servicios estaba incurriendo, en primer lugar se le eximiese del pago de la parte que le correspondiese abonar del total de la multa que se había impuesto a la comunidad judía bilbilitana por los delitos sobre los que había estado investigando la Inquisición ${ }^{52}$. En segundo lugar que se le autorizase a vender sus heredades libremente, sin tener que contribuir a la hacienda regia con parte del precio obtenido de la venta. En tercer lugar que se le permitiese reclamar el pago de las cantidades que se le adeudaban por préstamos que había efectuado con «logro», es decir, en los que se habían exigido intereses usurarios, liberándole además de la obligación de tener que entregar al rey el derecho que le correspondía percibir sobre dichas cantidades. Y, por fin, en cuarto lugar, que sólo tuviese que responder con su persona y bienes del pago de su propia pecha, de modo que, una vez

\footnotetext{
${ }^{49}$ Referencias a la situación de la infanta María tras la muerte de su esposo se pueden encontrar en mi «Vicisitudes de un gran estado señorial en la frontera de Castilla con Aragón durante la primera mitad del siglo XIV: Los señoríos sorianos del infante Don Pedro», AEM 35 (2005), 47-90.

${ }^{50}$ RÉGNÉ, History, pág. 611, doc. 3337, que remite a ACA, C, reg. 227 - 197, Calatayud, 4VII-1325.

${ }^{51}$ Vid. BAER, Die Juden... Aragonien, doc. 186, págs. 247-248; carta de la infanta María a Jaime II, fechada en Calatayud, 10-XII-1326.

${ }^{52}$ Se refiere a las actuaciones del inquisidor fray Guillermo Costa en la judería de Calatayud en los años 1324-26. Entonces fueron impuestas unas severas penas a la aljama judía bilbilitana y a cada uno de sus miembros, por los delitos de circuncisión de dos cristianos, y apostasía de un judío bautizado que había vuelto a profesar la religión judía. En febrero de 1327 el rey suspendió la aplicación de estas penas, que habría conllevado la destrucción de la judería, a cambio del pago de una multa de $20.000 \mathrm{~s}$. j. Vid. RéGNÉ, History, pág. 625, doc. 3419, reg. 229 - 239v, Barcelona, 6-II-1327.
} 
que la hubiese abonado, no se le pudiesen embargar sus bienes, ni apresarle a él, por razón del incumplimiento del pago de impuestos en que incurriesen otros miembros de la aljama ${ }^{53}$.

Otros documentos de la cancillería de Jaime II nos proporcionan, por su parte, testimonios adicionales sobre la variedad de modalidades que adoptó el régimen de exención de que disfrutaron algunos judíos bilbilitanos. A título ilustrativo nos limitaremos a dejar constancia de dos ejemplos. En primer lugar el de Jacob Avenhalez (¿Abenabez?), a quien en 1312 concedió este monarca la exención de todo impuesto durante diez años, para compensarle por los perjuicios sufridos como consecuencia de unas inundaciones que habían afectado a sus casas ${ }^{54}$. Y, en segundo lugar, el de los hermanos Iaffudá y Mossé del Calvo, a quienes en 1321 ordenó que en adelante sólo se les repartiesen tres sueldos, cuatro dineros y un óbolo en cada «arca» o derrama, para ayudarles a sobrellevar el grave perjuicio económico que les había ocasionado la muerte de un caballo que recientemente habían comprado, por el que habían pagado la elevada suma de 1.500 s. j. ${ }^{55}$.

\section{ActiVIDAdes FINANCIERAS}

La atención prestada hasta ahora a las familias francas de Calatayud nos ha llevado a aludir reiteradamente a la importante actividad desarrollada por algunos de sus miembros como financieros y recaudadores de impuestos al servicio de la monarquía. A esta actividad, no obstante, no se dedicaron exclusivamente los judíos francos, sino que también otros miembros de la comunidad judía bilbilitana de posición más modesta participaron en la misma, aunque por regla general en negocios de menor envergadura, como nos testimonia el caso de Mossé Albí, que tuvo a su cargo en varios ejercicios a principios del siglo XV la renta del peaje de Calatayud ${ }^{56}$. Y en otras ocasiones ejercieron de simples subarrendadores, como Iucef Paçagón, quien en 1349 tenía tomada a renta de su

${ }^{53}$ BAER, Die Juden... Aragonien, doc. 184. Aunque el documento no está fechado, es muy probable que corresponda al año 1326. También interesa consultar a este respecto el doc. 183, carta de la infanta María a Jaime II, fechada en Calatayud, 11-V-1326.

${ }^{54}$ RÉGNÉ, History, pág. 548, doc. 2962, que remite a ACA, C, reg. 209 - 233, Calatayud, 20XII-1312.

${ }^{55}$ RÉGNé, History, pág. 584, doc. 3172, que remite a ACA, C, reg. 219 - 216, Valencia, 27 I-1321.

${ }^{56}$ En 1403 era arrendador de dicho peaje junto con Florencio Pérez de Azna, también vecino de Calatayud. ACA, C, reg. 2139 - 58, Valencia, 13-XII-1403. En 1407 lo tenía tomado a renta él solo, ACA, C, reg. 2151 - 129v, Valencia, 15-IV-1407.

Sefarad, vol. 67:2, julio-diciembre 2007, págs. 327-365. ISSN 0037-0894 
convecino cristiano Martín López de Uncastillo la renta del peaje de las bestias que se vendían el martes en el mercado de Calatayud ${ }^{57}$.

La recaudación de impuestos estuvo con frecuencia asociada al préstamo, debido a que los arrendadores adelantaban a la monarquía el dinero que más adelante ellos percibían de los contribuyentes. De ahí que los más destacados hombres de negocios de la comunidad judía bilbilitana, y muy en particular los francos, fuesen por encima de todo prestamistas que atendían las necesidades de liquidez no sólo del aparato hacendístico de la monarquía sino de otras muchas instancias, cargando a los beneficiarios de los adelantos unos intereses que presumimos que debían ser muy elevados, pues también eran grandes los riesgos en que incurrían al realizar este tipo de operaciones. Por ello no resulta sorprendente que en ocasiones llegasen a ser denunciados y condenados como usureros, según nos confirma, por ejemplo, un documento del año 1410 que informa de ciertas sentencias pronunciadas en la Real Audiencia contra Sol Alatzar, judía de Zaragoza, y Samuel Abensaprut y Salamón Abendahuet, hijo de Iucef Abendahuet, judíos de Calatayud, a instancias de Don Juan Don Sancho, mercader de Zaragoza, por ciertas «usuras y logros» que aquéllos le habían llevado ${ }^{58}$. Este último fue de hecho uno de los principales recaudadores de impuestos al servicio de los reyes de Aragón en el tránsito del siglo XIV al XV, y ya había mantenido diferencias en varias ocasiones con anterioridad con la familia Abendahuet, que, al igual que él, destacó por su activo papel en tareas de recaudación de impuestos al servicio de la monarquía ${ }^{59}$. Pero el hecho de que este reputado financiero zaragozano llegase a acusar de usurero a un miembro de esta familia judía nos proporciona un interesante indicio para comprender el carácter de las transacciones financieras sobre las que se sustentaba el funcionamiento de la Real Hacienda aragonesa, que sin duda contribuyeron de forma decisiva a incrementar la fortuna del selecto grupo de judíos que tuvieron participación en ellas.

La solvencia financiera de algunos judíos bilbilitanos propició por otra parte que actuasen en ocasiones como fiadores de cristianos en operaciones en que éstos tomaron a préstamo importantes cantidades de dinero, a veces para atender necesidades de la propia monarquía. Las razones por las que accedieron a

${ }^{57}$ ACA, C, reg. 656-66, Valencia, 14-XII-1349.

58 ACA, C, reg. 2162-118v, Barcelona, 5-IV-1410. Carta dirigida a los rabinos de las aljamas de Zaragoza y Calatayud, para que impidan a los referidos tres judíos la entrada a las sinagogas hasta que no hayan ofrecido satisfacción a Juan Don Sancho conforme a lo dispuesto en las sentencias pronunciadas contra ellos.

${ }^{59}$ Por ejemplo en 1404 el rey encargó al baile de Calatayud que entendiese en todas las causas que trataba de mover Juan Don Sancho contra Iucef Abendahuet, judío de Calatayud. ACA, C, reg. 2144-9, Barcelona, 2-IX-1404. 
desempeñar este papel, muy arriesgado, pues en caso de que el prestatario principal no devolviese el dinero en los plazos fijados en el contrato era el fiador el que debía responder con sus bienes del pago, no se aclaran en los documentos conservados, pero es probable que exigiesen una compensación económica del prestatario a quien fiaban, por razón del riesgo en que incurrían al hacerlo. Y que éste no era irrelevante nos lo demuestra, por ejemplo, lo que le ocurrió en 1359 a Mossé Abensaprut, quien se ofreció como fiador cuando el consejero del rey de Aragón Pedro Jordán de Urriés tomó prestados del mercader bilbilitano Pascasio Ponce $1.200 \mathrm{~s}$. j. para atender una necesidad financiera de la propia monarquía. Pedro Jordán de Urriés no debió, sin embargo, devolver puntualmente el dinero; y, como consecuencia, a comienzos del año 1359 Pascasio Ponce ya había puesto en marcha el procedimiento judicial para que se hiciese ejecución en bienes de Mossé Abensaprut, obligando así a intervenir a Pedro IV, quien le rogó por carta que esperase algún tiempo a recuperar su dinero, guardando consideración al hecho de que había sido tomado a préstamo para servicio del rey ${ }^{60}$.

El negocio del préstamo, en el que participaron con diferente grado de dedicación muchos judíos vecinos de Calatayud a lo largo del siglo XIV, tuvo, no obstante, otras muchas manifestaciones más allá del mundo de las altas finanzas cortesanas, y del entorno de la familia real ${ }^{61}$. En efecto, fueron muchas y variadas las personas e instituciones que tomaron entonces a préstamo cantidades de dinero de muy diversa envergadura de judíos bilbilitanos, a juzgar por las noticias aportadas por la documentación cancilleresca; no obstante, hay que tener en cuenta que esta documentación proporciona una información de carácter fragmentario y sesgado, dado que sólo recoge casos en que las operaciones dieron lugar con posterioridad a pleitos, bien porque se las consideró de carácter usurario, o porque los prestatarios incumplieron los compromisos contraídos con sus correspondientes prestamistas.

En cualquier caso, a pesar de las limitaciones de este tipo de información, ésta no deja lugar a dudas sobre la amplitud y diversidad de la clientela que recurrió a los servicios financieros de los judíos bilbilitanos. Así, en primer lugar, hay que destacar que éstos no se limitaron a negociar en el reino de Aragón, sino

${ }^{60}$ ACA, C, reg. 1161 - 85v Almunia, 18-I-1359, carta de Pedro IV a Pascasio Ponce, mercader de Calatayud.

${ }^{61}$ Sobre la actividad de Açach Abenalahud como prestamista de la infanta María, hija de Jaime II, vid. supra. Otro miembro de la familia real que recibió préstamos de judíos bilbilitanos fue el infante Pedro, hermano de Jaime II. Vid. ACA, C, reg. 171-75, Valencia, 2-I-1321. Comisión al baile de Calatayud para que investigue sobre la denuncia presentada por el infante Pedro contra Açach Selludo, judío de Calatayud, que se negaba a reintegrarle ciertas prendas que le había entregado en garantía por razón de cierta cantidad de dinero que le debía, a pesar de que ya se la había devuelto.

Sefarad, vol. 67:2, julio-diciembre 2007, págs. 327-365. ISSN 0037-0894 
que también realizaron numerosas operaciones en el reino de Castilla, donde entre sus clientes se contaron algunas corporaciones de gobierno local, como, por ejemplo, el concejo de Atienza, a quien efectuó préstamos nuestro conocido Salamón Abendahuet ${ }^{62}$, o algunos sexmos de la Universidad de la Tierra de Soria, como el de Frentes, que en 1397 fue condenado por el gobernador de Aragón a pagar a Mossé Albí 800 florines que le adeudaba por virtud de contrato notarial de obligación ${ }^{63}$. Y, al margen de estas operaciones con instituciones, también realizaron otras muchas con personas particulares, en su mayoría campesinos vecinos de aldeas próximas a la frontera ${ }^{64}$.

Dentro del reino de Aragón, entre quienes recibieron dinero prestado de judíos de Calatayud cabe mencionar en primer lugar a algunas instituciones eclesiásticas como el monasterio de Santa María de Piedra, que en los primeros años del siglo XIV sigue un pleito contra algunos de ellos (Jacob Abenhorra, Salil Abenhorra, Ibrahim Albí, Iucef Albí, Açach Abentabas y Salomón), a los que acusaba de haber prestado el dinero con usura ${ }^{65}$. También tomaron dinero a préstamo de judíos bilbilitanos algunas corporaciones de gobierno local, como la Comunidad de aldeas de Calatayud ${ }^{66}$, o determinados concejos aldeanos, como el de Llumes ${ }^{67}$. Mucha más importancia alcanzaron, sin embargo, por su número y por sus repercusiones sociales y políticas, los préstamos efectuados a campesinos de las aldeas de la Comunidad de Calatayud, o de otros ámbitos

${ }^{62}$ ACA, C, reg. 828 - 163, Monzón, 8-VIII-1383. Salamon Abendahuet había denunciado que la universidad y personas singulares de Atienza y sus aldeas, que se habían obligado por instrumentos públicos otorgados en Calatayud a pagarle ciertas cantidades de dinero, desde hacía cierto tiempo habían dejado de acudir a esta ciudad, dirigiéndose por el contrario a Valencia, Daroca y Teruel, para así no verse forzados a pagarle lo que le debían.

${ }^{63}$ ACA, C, reg. 2119-69v, Zaragoza, 17-XII-1398. Mossé Albí, judío de Calatayud, había obtenido sentencia del gobernador de Aragón, pronunciada en Calatayud 5-XII-1397, por la que condenaba a los hombres pecheros de todas las aldeas del sexmo de Frentes, en la Tierra de Soria, y a unos vecinos en particular de las aldeas de Villaciervos, Herreros, Oteruelos, Vinuesa y Cidones, a pagarle 800 florines de oro de Aragón, que éstos se habían obligado por instrumento público a entregarle, renunciando a la jurisdicción de sus propios jueces locales.

${ }^{64} \mathrm{Vid}$. mi «La movilidad de los judíos a ambos lados de la frontera entre las Coronas de Castilla y Aragón durante el siglo XIV», Sef 63 (2003), 262 y ss.

${ }^{65}$ ACA, C, reg. $126-198 \mathrm{v}$, Tortosa, 1-I-1303.

${ }^{66}$ Vid. ACA, C, reg. 237 - 31, Valencia, 30-III-1309. Se hace constar que hacía un tiempo el escribano y adelantados de la Comunidad de aldeas de Calatayud habían tomado a préstamo de Iucef Abenalahud, judío de Calatayud, cierta cantidad de dinero.

${ }^{67}$ El concejo de Llumes por contrato de 22-VIII-1385 vendió a Garcí Pérez de Matos, escribano de la universidad de aldeas de Calatayud, un molino por $3.000 \mathrm{~s}$. j. para hacer frente a unas deudas que tenía contraídas con Don maestre Xacó Azarías y con Don Bienvenist Arruet, judíos vecinos de Calatayud. Noticia en AHN, Clero, leg. 8511. 
jurisdiccionales próximos, tanto de realengo como de señorío. La documentación cancilleresca, en efecto, proporciona abundantes noticias, de carácter más o menos concreto, relativas a este tipo de operaciones, que dan testimonio de su notable difusión, y además permiten identificar algunas de las principales razones por las que entre estos campesinos arraigaron los prejuicios antijudíos.

Ya en los primeros años del siglo XIV el fenómeno había alcanzado grandes proporciones, y se había convertido en una fuente de enfrentamientos y conflictos entre los campesinos y los judíos bilbilitanos, por lo que el rey Jaime II decidió intervenir para atajarlos e imponer una solución de concordia que hiciese posible la restauración de la paz social. Para ello ordenó, por un lado, a los adelantados y universidad de las aldeas de Calatayud que enviasen como sus procuradores a la Corte a Martín Aznar de Miedes y al escribano de la institución, con plena potestad para poder firmar ante notario un acuerdo que diese solución al problema de las deudas contraídas por vecinos de las aldeas con los judíos de Calatayud, acatando lo que el rey ordenase al respecto. E idéntica orden transmitió a la aljama de judíos bilbilitana, exigiéndole que enviase como sus procuradores a Iucef Abenalahud y a otros tres judíos más ${ }^{68}$.

El origen de las desavenencias planteadas entre los judíos y los campesinos de las aldeas en aquella ocasión no es aclarado en los documentos consultados. Pero, por indicios, presumimos que tenían relación con la indisposición de éstos últimos a hacer efectivos los pagos comprometidos en los contratos notariales firmados, en los plazos en ellos fijados, probablemente con la excusa de que en ellos había intervenido usura. Sea como fuere, finalmente ambas partes llegaron a un acuerdo transaccional que fue confirmado por el monarca, en virtud del cual éste concedió una moratoria a los vecinos de las aldeas para el pago de las deudas contraídas con los judíos, pero a condición de que quedasen comprometidos a efectuar los pagos en los nuevos plazos contemplados en dicha moratoria, sin ningún tipo de excusa ${ }^{69}$. Y, además, fueron nombrados dos diputados, Martín Aznar de Miedes y Iucef Abenalahud, para que examinasen las cuestiones concretas que en torno al cumplimiento del acuerdo llegasen a plantearse, las cuales, aunque nada se dice al respecto en los documentos, entendemos que podían estar relacionadas con el problema de determinar si en los

${ }^{68}$ ACA, C, reg. 128 - 198, Teruel, 9-VII-1303.

${ }^{69}$ Así se hace constar en ACA, C, reg. 134, s. f. Valencia, 17-XII-1304. En este documento el rey Jaime II hace alusión a una «carta ordinationis seu elongamenti» que él había otorgado, conforme a lo dispuesto en la transacción a la que habían llegado los aldeanos y los judíos, y que él había confirmado. 
contratos había intervenido o no usura ${ }^{70}$. Sea como fuere, a pesar de las concesiones efectuadas a los campesinos en el acuerdo transaccional, muchos de ellos continuaron mostrando resistencia a cumplir con los compromisos contraídos, y así se reconoció en una carta que más de un año después de firmarse el acuerdo envió Jaime II a Martín Aznar de Miedes y Iucef Abenalahud, en la que recogía la denuncia presentada por los representantes de la aljama judía de Calatayud contra los aldeanos, que no habían querido pagar sus deudas en los plazos fijados en el acuerdo transaccional ${ }^{71}$.

Estos conflictos de los años 1303 y 1304 no tuvieron, sin embargo, carácter excepcional sino que una y otra vez los vemos resurgir a lo largo del siglo XIV, aunque, por tratarse de una cuestión de interés secundario en el contexto del presente trabajo, no vamos a entrar a dar cuenta pormenorizada de las noticias reunidas al respecto. Nos limitaremos a dejar constancia de que en unas ocasiones se trata de denuncias del cobro de usuras por los judíos, en otras de solicitudes al rey de concesiones de moratorias, y en otras, por fin, de denuncias de los procedimientos fraudulentos a los que recurrían los campesinos para escapar a su obligación de pagar las deudas contraídas con los judíos, entre los que destacaban las donaciones fingidas de sus bienes a terceras personas para evitar que se hiciese ejecución en ellos por los oficiales de la justicia. La propia abundancia de noticias confirma en cualquier caso que el préstamo a los campesinos que atravesaban por dificultades financieras fue una actividad a la que se dedicaron muchos miembros de la comunidad judía bilbilitana, hasta el punto de que la propia aljama como institución asumió la defensa de sus intereses cuando se plantearon conflictos en torno a su práctica, bien por razón de denuncias presentadas por el cobro de usuras, o bien con motivo de resistencias ofrecidas por los deudores a cumplir con los compromisos contraídos con los prestamistas.

Sin embargo, no todos los campesinos del entorno de Calatayud eran en el siglo XIV cristianos, sino que también había entre ellos entonces bastantes sarracenos, que al igual que aquéllos recurrieron a los judíos bilbilitanos como fuente de crédito. En concreto cabe destacar el papel desempeñado por los miembros de la familia Abenalahud como prestamistas para los integrantes de esta comunidad étnico-religiosa, que en las primeras décadas del siglo XIV siguieron plei-

\footnotetext{
${ }^{70}$ En los documentos simplemente se califica a estos dos individuos como «examinadores y determinadores» diputados «super debitis quod per aldeanos aldearum Calataiubii debentur judeis Calataiubii», para que conociesen «super questionibus quas inter dictos aldeanos et judeos contingerent».

${ }^{71}$ ACA, C, reg. 134 - 234v, Zaragoza, 11-VI-1304; y reg. 134, s. f., Valencia, 17-XII-1304.
} 
tos con al menos tres aljamas sarracenas aragonesas, las de Villafelich, Brea ${ }^{72} \mathrm{y}$ Aranda ${ }^{73}$, por razón de problemas con que tropezaban para recuperar numerosas partidas de dinero prestadas tanto a las aljamas como a miembros singulares de las mismas. Pero también disponemos de noticias sobre préstamos efectuados por otros judíos bilbilitanos a vecinos de otras aljamas sarracenas del reino de Aragón, tales como Isaac Abenalaphuf, con el que en 1326 tenían contraídas deudas los sarracenos de Cariñena ${ }^{74}$, o Daigón (¿por Maimón?) Abenrodrich a quien en 1351 le debía cierta cantidad de dinero por instrumentos públicos la aljama sarracena de Jarque, del señorío de Juan Fernández de Luna ${ }^{75}$.

Por fin, para terminar con esta somera relación de instituciones y grupos sociales que conformaron la clientela de los judíos bilbilitanos en sus operaciones de préstamo de dinero con interés, no podemos dejar de mencionar a los propios vecinos de la ciudad de Calatayud, tanto cristianos ${ }^{76}$ como judíos $^{77}$. No debe-

${ }^{72}$ Noticia sobre los pleitos que seguían Iucef Abenalahud y sus hijos contra las aljamas de sarracenos de Brea y Villafelich, y algunos sarracenos singulares de ellas, sobre dinero que debían a los judíos en ACA, C, reg. 134 - 22, Calatayud, 27-I-1305.

${ }^{73}$ Sobre los pleitos seguidos por Iucef Abenalaud y sus hijos (de entre los cuales se cita expresamente a Ismael) contra los sarracenos de Aranda y su aljama vid. entre otros documentos: ACA, C, reg. 134, s. f., Valencia 17-XII-1304. Iucef Abenalahud, por sí y en nombre de sus hijos, había denunciado dificultades en el cumplimiento de una orden dada al justicia de Calatayud en 1303 para que obligase a los sarracenos de Aranda a pagar las cantidades que adeudaban a dicho judío, sin atender a la carta de moratoria que el rey había concedido a dichos sarracenos. Reg. 148-190, Daroca, 16-XI-1311 (noticia del pleito que siguen Iucef Abenalahud y sus hijos contra la aljama de sarracenos de Aranda). Y reg. 149, s. f., 17-XII-1311, convocatoria a Ismael Abenalahud y sus hermanos para que comparezcan en la Corte para examinar los contratos de obligación concertados entre ellos y los sarracenos de Aranda.

74 ACA, C, reg. 185 - 242, Barcelona, 2-I-1326.

75 ACA, C, reg. 665 - 168.

${ }^{76}$ A título meramente ilustrativo mencionaremos sólo dos ejemplos, el de Pascasio Franco que «forzado por la necesidad» tomó a préstamo cierta cantidad de dinero de Salamón de Quatorze (ACA, C, reg. 611 - 9v, Barcelona, 11-XII-1340), y el de la mujer de Matheo del Bispe, quien había recibido en préstamo de un judío de Calatayud cierta cantidad de dinero, y para más seguridad le había efectuado venta al judío de un huerto, con condición de que, una vez que ella le hubiese devuelto el dinero prestado, éste le devolvería el huerto (ACA, C, reg. 131 - 115v, Calatayud, 20-III-1304: carta de Jaime II al deán de Calatayud para que atienda la demanda presentada por la mujer de Matheo del Bispe, que había denunciado que el judío no quería devolverle el huerto como estaba obligado).

${ }_{77}$ En la documentación cancilleresca se recogen bastantes denuncias de judíos de Calatayud que no pueden cobrar determinadas cantidades de dinero que les adeudan otros judíos de la misma ciudad, aunque no suele indicarse de forma expresa que el origen de la deuda estuviese en operaciones de préstamo de dinero. En muchos casos podía tener otro origen, por ejemplo en una transacción comercial en la que se había concedido aplazamiento de pago, o en la liquidación de cuentas de una compañía. 
mos olvidar, en efecto, que en el seno de la comunidad judía bilbilitana hubo muchos individuos que se desenvolvían en situaciones financieras muy precarias, que les forzaban con frecuencia a tomar prestado dinero para atender sus urgentes necesidades. Y, paradójicamente, ni éstos como personas particulares ni la aljama como institución recurrieron siempre a otros judíos para que se lo prestasen, sino que con relativa frecuencia sus prestamistas fueron cristianos. Así lo confirman en concreto algunas concesiones de moratorias efectuadas por los reyes de Aragón a la aljama judía de Calatayud, y a sus miembros singulares en particular, por las que les concedían espera para el pago de las cantidades que adeudaban a cristianos ${ }^{78}$. Y a estas noticias hay que añadir las numerosas referencias a casos particulares contenidas en la documentación cancilleresca, que dan fe, por ejemplo, de la frecuencia con que judíos bilbilitanos tomaron dinero a préstamo de mercaderes foráneos, en su mayoría catalanes, que negociaban en el entorno de Calatayud ${ }^{79}$.

Por lo que se refiere a la identidad y perfil socioeconómico de los judíos bilbilitanos que practicaron el préstamo de dinero con interés cabe decir que, en el estado actual de las investigaciones, resulta arriesgado hacer valoraciones de carácter general al respecto, máxime teniendo en cuenta el carácter fragmentario de nuestras informaciones. Pero al menos sí consideramos digno de resaltar el hecho de que algunas de las familias que por indicios nos consta que se contaron entre las más acaudaladas e influyentes de la aljama destacaron también por ser las más activas en este negocio, a juzgar por el número de veces que aparecen noticias relativas a ellas en la documentación cancilleresca, y por el carácter de dichas noticias. A este respecto resulta paradigmático el caso de Iucef Abenalahud, y sus hijos Ismael, Mossé y Açach. En efecto, ya vimos cómo esta familia hacia 1320 contaba con riqueza suficiente como para quedar obligada a contribuir con al menos una

78 Vid. ACA, C, reg. 178 - 27, Tarragona, 8-X-1322. Referencia a la moratoria concedida por dos años por el rey a la aljama de judíos de Calatayud y a los judíos singulares de ella por las deudas que debiesen a cristianos hasta en cuantía de 2.000 s. j. Reg. 148 - 173, Zaragoza, 30-X-1311. Guillermo de la Catalana, vecino de Daroca, seguía pleito contra la aljama de judíos de Calatayud por razón de una moratoria que ésta había conseguido del rey por cantidad de 3.000 torneses de plata que había recibido en préstamo del referido Guillermo de la Catalana.

${ }^{79}$ Entre otras referencias documentales sirvan a título ilustrativo las siguientes: ACA, C. reg. 2121 - 166 (Cerdán Soriguera, mercader de Puigcerdá, había prestado en pura comanda a Ibrahim Frangil y Iucé Frangil, judíos de Calatayud, 97 florines que éstos no le querían restituir); reg. 2120 - 178 (Bernard Jaulent, mercader de Puigcerdá, había confiado en comanda a un judío de Calatayud 200 libras de dineros jaqueses, que en 1378 su hijo Joan todavía no había conseguido cobrar); reg. 1830 - 77v, Barcelona, 22-X-1387 (noticia de préstamos efectuados por Jaume Mauri, mercader de Puigcerdá, a Caçón Chiliela y Samuel Abensapont [¿por Abensaprut?], judíos de Calatayud). 
décima parte del total de impuestos repartidos por la aljama. Por su parte, también vimos cómo uno de sus miembros, Açach Abenalahud, prestó valiosos servicios financieros a la infanta María, hija de Jaime II, adelantándole importantes sumas de dinero para atender sus necesidades, que ésta trató de compensar solicitando a su padre que le concediese una serie de privilegios. Y ahora, al analizar la información reunida sobre la actividad de los judíos bilbilitanos como prestamistas, hemos podido comprobar que durante la primera mitad del siglo XIV tanto Iucef como sus hijos ocuparon un lugar de primera fila en este negocio.

En cualquier caso, aunque parece probable que unas pocas afortunadas familias acaparasen la mayor parte del negocio del préstamo con interés, al menos en sus parcelas más rentables, también es cierto que fueron muchos y de muy diverso perfil los miembros de la comunidad hebrea bilbilitana que realizaron incursiones en el mismo. Y sabemos, por otra parte, que algunos lo hicieron por vía indirecta, entregando dinero propio a otros judíos para que lo empleasen en operaciones de préstamo, y luego les rindiesen cuentas del empleo dado al mismo ${ }^{80}$.

Para concluir este capítulo, interesa hacer una breve referencia a la dedicación de algunos judíos bilbilitanos al oficio de cambiadores, que con frecuencia estuvo asociado a la práctica del préstamo con interés y a la prestación de otro tipo de servicios financieros, como las transferencias de dinero entre distintos clientes, a veces entre diferentes plazas. El número de judíos que desempeñaron este oficio en Calatayud debió ser relativamente elevado, a juzgar por las referencias encontradas en la documentación cancilleresca. De la mayoría de ellos sólo conocemos, sin embargo, el nombre, como es el caso de Jacob Abenhalén, que lo era en $1319^{81}$, de Issach Perav ${ }^{82}$, y de Açac Abensaprut Izquierdo y su hermano Salomón, Brahem Paçagón y Açac Amancaya (¿Avnacaya?), quienes en 1352 poseían tiendas de cambios en la alcaicería, propiedad del monasterio de Piedra ${ }^{83}$. Pero de otros conocemos también algunos detalles relativos al tipo

${ }^{80}$ Un ejemplo en ACA, C, reg 786 - 130v, Monzón, 28-VIII-1376. Iucé Meçaput (¿por Abensaprut?) Esquerdo, judío de Calatayud, había informado que él había entregado ciertas cantidades de dinero a Salamón Millán, judío de Calatayud, que éste le prometió «administrare, procurare et mutuare ad usuras fidelite atque bene», y después rendirle cuentas. Después le reclamó rendimiento de cuentas y la devolución del dinero, a lo cual Salamón Millán se negó.

${ }^{81}$ ACA, C, reg. 171 - 25, Valencia, 19-XII-1319.

${ }^{82}$ ACA, C, reg. 787 - 34v, Monzón, 8-VII-1376. Comisión al baile de la aljama de judíos de Calatayud para que conozca sobre una denuncia presentada por Issach Perav, judío cambiador, por haberle robado gran cantidad de dinero que tenía «in hospita suo in quo hospitabant» Iucef Ripal, judío de Calatayud, y su mujer.

83 Vid. C. de la Fuente Cobos, «La alcaicería de Calatayud y el monasterio de Piedra», en I Encuentro de Estudios Bilbilitanos (Calatayud 1983), 149-163, en concreto, pág. 152, nota 26. 
de operaciones financieras que realizaron. Así, Mossé Analcavit en 1370 confesó haber efectuado diversas «ditas» como cambiador a varios mercaderes, en cantidad que sumaba más de 6.000 s. j., en nombre de Saúl Albí y su hijo Mossé, judíos también vecinos de Calatayud ${ }^{84}$. Y por su parte Salamó Vindeuch estaba involucrado en 1352 en un negocio de cambios de moneda castellana concertado con el caballero castellano Alfonso Fernández de Jaén y con el mercader bilbilitano Juan Fina ${ }^{85}$.

\section{Actividades MERCANTILES}

La ciudad de Calatayud se consolidó en el siglo XIV como uno de los principales centros mercantiles del reino de Aragón, que asumió un importante papel en la canalización de las relaciones comerciales con el reino de Castilla ${ }^{86}$. Y la contribución de la comunidad judía a este proceso fue notable porque fueron muchos los miembros de la misma que se dedicaron a la actividad mercantil durante ese siglo.

En primer lugar así podemos constatarlo en el ámbito concreto del comercio de paños, que fue sin duda el que más contribuyó entonces a hacer de Calatayud un centro mercantil de primera fila en su entorno. Los judíos bilbilitanos habían sido autorizados por privilegio del rey Jaime I de 1264 a tener abiertas tiendas de venta de paños, pero éstas debían instalarse necesariamente en la alcaicería, propiedad del monasterio de Santa María de Piedra, por virtud de una permuta realizada por iniciativa del rey en $1219^{87}$. En la práctica, durante el siglo XIV, sin embargo, fueron bastantes los judíos que no observaron esta disposición e instalaron tiendas de paños fuera de la alcaicería. Así lo demuestran en concreto algunas noticias de multas impuestas a instancias del monasterio a varios de ellos, que, por ejemplo, en 1337 superaron la decena ${ }^{88}$. Y, dado que entre los

${ }^{84}$ ACA, C, reg. 1618-226v, Zaragoza, 28-XI-1370. Mosse Abnalcavit había denunciado que Saúl Albi y su hijo Mosse no querían abonarle las cantidades que él en su nombre había abonado a varios mercaderes.

${ }^{85}$ ACA, C, reg. 666-94, Lérida, 28-IV-1352.

${ }^{86} \mathrm{Vid}$. mi «Desarrollo de las ciudades aragonesas fronterizas», y también mi «Calatayud en la Baja Edad Media. Organización sociopolítica y actividades económicas», en Sexto Encuentro de Estudios Bilbilitanos (Calatayud 2005), 237-274.

87 Sobre esta cuestión vid. Fuente CoBos, «La alcaicería de Calatayud».

${ }^{88}$ Los judíos multados en 1337 por tener instaladas tiendas de paños fuera de la alcaicería fueron, según la transcripción ofrecida por Fuente Cobos: Mossé Abensaprut; Iantó Capantón y Iantó Abensomer; Astruc, hijo de Rabí Sentó; Iucef de Quatorze y Çadoc del Rabí; Rabí Serón, 
ocupantes de las veintiuna tiendas que había en la alcaicería bilbilitana en 1344 se constata la presencia de al menos diez judíos ${ }^{89}$, parece bastante probable que el total de miembros de esta comunidad que entonces se dedicaban a la venta al por menor de paños en Calatayud superase con creces la veintena. Además, conviene también tener en cuenta que varios de ellos participaron en este negocio como miembros de compañías en las que uno de los socios era un mercader cristiano. Es el caso de Salamón y Mossé Alfaçán, que en 1377 tenían en sociedad una tienda de paños con el mercader Berengario Flechos, en la que vendían paños que previamente habían adquirido a crédito de otros mercaderes, y que ellos a su vez solían vender a crédito a muchos de sus clientes ${ }^{90}$.

El comercio de paños se sustentaba, en efecto, en esta época en Calatayud sobre un complejo sistema crediticio, de forma que eran raras las transacciones que se cerraban con pagos al contado, sobre todo cuando afectaban a paños que no eran de producción local. Los judíos dedicados a este negocio siguieron los mismos procedimientos que sus colegas cristianos. Así, por un lado, tenemos noticia de que contrajeron importantes deudas con mercaderes foráneos, en su mayoría catalanes, que les proveían de paños al por mayor, como hizo Iucef de Quatorze, quien en una ocasión, en la década de 1330, adquirió de unos mercaderes extranjeros una partida de paños de diversos colores por valor de 1.772 s. j. que se obligó a hacerles efectivos en varios plazos ${ }^{91}$. En 1337 éste, identificado como hijo de «Sançón» de Quatorze, figuraba entre los que tenían abierta tienda de paños fuera de la alcaicería, constando que la suya se ubicaba en concreto en la propia judería. Poco tiempo después, en 1341, presentó una petición al rey junto con su hijo Jacob, para que se les autorizase a vender paños en sus propias casas siempre que continuasen abonando al monasterio de Piedra

Moisés Zabadías, Xantó Compacón, Xantó Abensomer y Moisés Daroca, $c f$. FuEnTE CoBos, «La alcaicería de Calatayud», pág. 153.

${ }^{9}$ Vid. Fuente Cobos, «La alcaicería de Calatayud», págs. 153-154. Los nombres de estos judíos eran, según la transcripción ofrecida por esta autora, Mossé Abenhalla, Azac el Izquierdo, Yacó Abensaprud, Yucé Pazagón, Yucé Acrih, Simuel Ovadiá, Mossé Abenhorna, Salomón Abenhorna, Yantó Gabay y Azac Ananalger.

90 ACA, C, reg. 792 - 84v, Barcelona, 17-IV-1377. Comisión a García Muñoz de Pamplona, jurisperito de Calatayud, para que tome cuenta a Berengario Flechos de los ingresos y gastos habidos en la tienda de paños que tenía en compañía con Salamón Alfaçán y Mossé Alfaçán.

${ }^{91}$ ACA, C, reg. 587 - 211, Castellón, 7-III-1337. Comisión a Alfonso Muñoz de Pamplona, baile de Calatayud. Es probable que este Iucef de Quatorze sea el judío del mismo nombre contra el que en 1342 se hizo un proceso inquisitorial, acusado de haber animado a retractarse de su conversión a un judío convertido al cristianismo; J. PERARNAU I EsPelt, «El procés inquisitorial barceloni contra els jueus Janto Almuli, la seva muller Jamila i Jucef de Quatorze (1341-1342)», Revista Catalana de Teologia 4 (1979), 309-353.

Sefarad, vol. 67:2, julio-diciembre 2007, págs. 327-365. ISSN 0037-0894 
el alquiler del obrador de la alcaicería, como se les estaba permitiendo de hecho hacerlo a otros judíos ${ }^{92}$. Y, por otros documentos, nos consta que también practicaba la venta a crédito de paños de elevada calidad, destinados a la confección de vestidos para acontecimientos extraordinarios de la vida social, como bodas. Así, por ejemplo, sabemos que hacia 1330 vendió a crédito a una vecina de Calatayud llamada Marquesa Pérez, mujer de Pedro Jordán, paños para la boda de su hijo por valor de $116 \mathrm{~s}$. j., con la condición de que ésta ofreciese un fiador, que se obligase con sus bienes al pago de dicha cantidad en caso de que ella incumpliese su compromiso ${ }^{93}$.

Iucef de Quatorze no representó, por otra parte, un caso aislado, sino que por el contrario la venta a crédito de paños a campesinos del entorno de Calatayud por parte de judíos vecinos de esta ciudad está ampliamente constatada en la documentación, y en ocasiones también fue denunciada por aquéllos como actividad usuraria. Así ocurrió, por ejemplo, cuando en 1321 los vecinos de Moros, aldea de la Comunidad de Calatayud, denunciaron a Mossé Abenalahud, Mayr Iucef de Quatorze, Açach Rarias (¿por Açarías?) y sus hijos, Jacob Abenforna y sus hijos, Azmel Abenhaluet, Salamon Passariel, hijo de Salamon Passariel, Açach del Rabí, y a los hijos de Almocaz, todos judíos vecinos de Calatayud, quienes les habían entregado en préstamo ciertas cantidades de dinero y paños «pro eorum vestibus», y desde entonces les estaban agraviando por múltiples vías, consiguiendo por medios fraudulentos duplicar y hasta triplicar el capital que quedaban finalmente obligados a devolverles ${ }^{94}$.

Teniendo en cuenta la importancia del crédito en el comercio de paños, nada tiene de sorprendente, por consiguiente, constatar que algunos mercaderes de paños judíos se dedicasen también al préstamo de dinero, según atestiguan diversos ejemplos. Y tampoco resultó inhabitual que algunos de ellos compaginasen estas actividades con el arrendamiento de rentas, formando para ello sociedades con otros judíos. Es el caso de Jacob Abensaprut, quien, según declaraciones de sus hijos Iucef y Salamón efectuadas en 1366, después de su muerte, había constituido en vida sociedades con otros judíos dedicadas al comercio, a la manufactura de paños y al arrendamiento de rentas ${ }^{95}$.

${ }^{22}$ ACA, C, reg. 616 - 74v, Poblet, 5-VII-1341.

${ }^{93}$ ACA, C, reg. $563-137 \mathrm{v}$, Zaragoza 8-XI-1330.

${ }^{94}$ ACA, C, reg.171 - 121, Valencia, 3-II-1321. Comisión a Pedro Garcés de Usa, baile de Calatayud, para que hiciese averiguación e impartiese justicia.

95 ACA, C, reg. 729-12v, Zaragoza, 25-VI-1366. Para calificar estas sociedades en el documento se utiliza la expresión «tam super facto mercatorie quam draperie quam arrendationum redditorum». 
Fuera del comercio de paños, los judíos bilbilitanos también se dedicaron a otras actividades mercantiles, negociando con otros productos, cuya identidad resulta más difícil de determinar por falta de referencias concretas en la documentación cancilleresca, que muchas veces se limita a utilizar el término genérico de «ciertas mercancías» para referirse a los productos con los que negociaban dichos judíos o las compañías mercantiles por ellos constituidas, bien con otros judíos o bien con cristianos ${ }^{96}$. En cualquier caso conviene precisar que, junto a la venta al por menor de tejidos y otras mercancías en las tiendas que tenían abiertas en la ciudad de Calatayud, otra interesante vertiente de la actividad mercantil desarrollada por algunos judíos bilbilitanos fue la del comercio al por menor de carácter itinerante, que practicaron tanto en el reino de Aragón como en el de Castilla.

En efecto, la documentación cancilleresca nos informa sobre viajes realizados por judíos de Calatayud a territorio castellano con acémilas cargadas de una amplia y variada gama de mercancías, para ser allí vendidas. Como muestra ilustrativa baste recordar el que hacia 1373 realizó Jucef Benvenist, a quien salieron a robarle hombres armados desde la fortaleza castellana de Vozmediano, cerca de Ágreda, cuando se dirigía a vender sus mercancías al reino de Castilla, tomándole treinta libras de azafrán, diez cajas llenas de confites, hilo de oro, fustán y un paño de Ripoll ${ }^{97}$.

Pero los judíos bilbilitanos no sólo se trasladaron a Castilla para practicar el comercio al por menor en régimen itinerante, sino que también concurrieron a algunas de las principales ferias que se celebraban en su territorio, para concertar en ellas operaciones de compra y venta de mercancías, sobre la naturaleza de las cuales no estamos, sin embargo, bien informados, porque la documentación consultada no aporta apenas detalles al respecto. En cualquier caso, como prueba de su presencia en dichas ferias baste recordar el suceso acaecido en 1328 a Mossé Passagón, judío vecino de Calatayud, quien, cuando regresaba de las de Alcalá de Henares, fue víctima de un robo perpetrado en un lugar de la Orden de Calatrava, donde le tomaron 200 mrs. de moneda castellana en ejecución de una carta de marca decretada contra vecinos de Molina y su Tierra, con el falso argumento de que él era vecino de esta villa castellana ${ }^{98}$.

Entre las múltiples facetas del negocio mercantil en las ciudades europeas bajomedievales, una de las más relevantes fue la del comercio de abastecimien-

${ }^{96}$ Un ejemplo de sociedad mercantil constituida por un judío con cristianos en ACA, C, reg. 655 - 163, Valencia, 20-III-1349. Iafudá Françés, también llamado Concho, judío de Calatayud, había informado que él había tenido sociedad mercantil con Matheo Tabaria, cuchillero de Calatayud, y con su hijo Francisco, a quienes por razón de la misma había efectuado algunos préstamos de dinero que éstos se habían obligado a devolverle.

97 ACA, C, reg. 766 - 23, Barcelona, 3-I-1373.

98 ACA, C, reg. $428-278$. 
to de productos alimenticios, que, sobre todo cuando se trataba de artículos de primera necesidad, estuvo fuertemente intervenido por las autoridades públicas. Éste era el caso en concreto del comercio de abastecimiento cárnico, en el que por supuesto los judíos bilbilitanos no pudieron dejar de participar, aunque sólo fuera por el hecho de que por imperativos religiosos la carne que se servía en las carnicerías de los cristianos no podía ser consumida por los miembros de la comunidad judía. Era, en efecto, necesario que hubiese carniceros judíos que sacrificasen los animales conforme a las prescripciones de la religión hebrea, aunque, tenemos constancia de que a principios del siglo $\mathrm{XV}$, a raíz de las muchas conversiones al cristianismo que tuvieron lugar en Calatayud, hubo algún período en que, por no haber ningún carnicero judío disponible, el rey concedió autorización a la aljama para que pudiese tener un carnicero cristiano hasta que encontrasen uno judío ${ }^{99}$. Pero el negocio del abastecimiento cárnico implicaba otras muchas actividades aparte del sacrificio de animales y venta al por menor de su carne. Y a este respecto llama la atención constatar que judíos vecinos de Calatayud participaron conjuntamente con cristianos en compañías dedicadas a este trato. Es el caso de Jacob Olbelía y Iucef Françés, ambos identificados como carniceros, que en 1316 formaban parte de una sociedad dedicada a la compra y venta de carnes para las carnicerías de Calatayud, junto con los cristianos Nicolás y Miguel de Molina y P. Navarro, de la que uno de sus miembros, Miguel de Molina, se había separado llevándose consigo parte del dinero perteneciente a la sociedad ${ }^{100}$.

Los carniceros judíos de Calatayud no formaron parte, en cualquier caso, del grupo más acaudalado e influyente de su comunidad, sino que por el contrario algunos indicios sugieren que disfrutaron de una posición más bien modesta, y entre ellos cabe destacar el hecho de que, como ya hemos indicado más arriba, estaban integrados en la mano «menor», junto con corredores, tejedores y otros menestrales. Algunos incluso llegaron a denunciar que se encontraban en situación de extrema pobreza, como hizo en 1356 Açach Figas, si bien, dado que la atribuyó a que en los últimos años se le habían cargado más impuestos de los que le correspondían por su posición económica, hay motivos para sospechar que había un tanto de exageración en la calificación de su situación personal ${ }^{101}$.

99 ACA, C, reg. 2456 - 186, Barcelona 22 VIII 1416. Sobre la contratación de un carnicero cristiano por la aljama de judíos de Zaragoza, vid. A. Blasco Martínez, «Significado del término matar en aragonés medieval. Un carnicero cristiano contratado para matar et tallar carne en la aljama de judíos de Zaragoza en 1401», Archivo de Filología Aragonesa 42-43 (1989), 259-275.

100 ACA, C, reg. 160 - 234, Poblet, 11-VI-1316.

101 ACA, C, reg. 687 - 192, Daroca, 12-XII-1356. 


\section{Artesanos}

A diferencia de lo que ocurre con los judíos dedicados a las finanzas y el comercio, la documentación cancilleresca aporta bastante menos información sobre los que tenían como principal o única dedicación alguna actividad artesanal. Por los indicios disponibles cabe presumir que los más numerosos fueron los ocupados en la manufactura textil, que, como ocurría en la mayoría de las ciudades europeas, también en Calatayud fue la más dinámica dentro del sector secundario de la economía. En concreto parece bastante probable que hubiese muchos judíos tejedores, pues, como ya hemos indicado, existió una cofradía que se llamó «de los tejedores», que dio nombre a una sinagoga ${ }^{102}$, y también se hace referencia explícita a ellos al hablar de los integrantes de la mano «menor». Pero otros, por su parte, se especializaron en las labores del tinte, como, por ejemplo, Abraham Azriello, a quien un cristiano vecino de Calatayud llamado G. Peyerno encargó hacia 1325 que instruyese a su hijo en el oficio de teñir paños, a cambio de prestarle $600 \mathrm{~s}$. j. sin cobrarle interés alguno ${ }^{103}$. Por indicios cabe a su vez presumir que algunos de los judíos que participaron en el negocio de la venta de paños fuesen empresarios que comercializaban tejidos que habían hecho fabricar por su cuenta a artesanos locales, bien de la ciudad o bien de las aldeas, a quienes proporcionarían la materia prima para ello. Pero en el estado actual de la investigación, y con las informaciones hasta ahora reunidas, no resulta posible afirmarlo con seguridad.

En cualquier caso no fue el textil el único sector manufacturero en el que tuvieron participación los judíos bilbilitanos, puesto que también nos consta que a mediados del siglo XIV varios de ellos se dedicaban al trabajo del cuero para la fabricación de abarcas. En concreto éstos, que residían en el entorno de la plaza del mercado mayor, fueron denunciados en 1361 porque extendían los cueros bovinos y de otros animales con los que trabajaban cerca de sus casas, generando como consecuencia un gran hedor en pleno centro de la ciudad. Y para evitar que así continuase ocurriendo en adelante, ordenó el rey entonces a las autoridades municipales que asignasen a dichos judíos abarqueros otro lugar donde pudiesen extender sus cueros para trabajarlos, prohibiéndoles el continuar haciéndolo en las inmediaciones del mercado ${ }^{104}$.

102 Vid. BAER, Studien zur Geschichte der Juden, págs. 167-168, según el cual, a fines del siglo XIV había en Calatayud una sinagoga llamada «escuela de los tejedores». Marín Padilla habla, sin embargo, de una cofradía que primero se llamó «de los tejedores», y luego «Sombre Holim», en su «Notas sobre la familia Lupiel», pág. 260.

103 ACA, C, reg. $183-124 \mathrm{v}$, Valencia, 16-IV-1325.

104 ACA, C, reg. $706-87 v$, Cariñena, 14-VI-1361.

Sefarad, vol. 67:2, julio-diciembre 2007, págs. 327-365. ISSN 0037-0894 


\section{Profesiones liberales}

La importancia alcanzada por la comunidad judía bilbilitana en el siglo XIV queda puesta de manifiesto en el número relativamente elevado de personas dedicadas a profesiones relacionadas con la actividad intelectual que nos consta que formaron entonces parte de ella. En concreto hay que destacar en primer lugar la abundancia de médicos, algunos de ellos de reconocido prestigio, que les valió ser requeridos incluso para servir a miembros de la familia real. Es el caso del ya mencionado maestre Salamón, que, según confesión de la infanta María del año 1326, les había prestado notables servicios como médico a ella y a su hija, doña Blanca, y de Abram Alcalay, que en 1320 desempeñaba el oficio de «rabino de la sinagoga mayor» de Calatayud y al mismo tiempo servía como médico personal a la reina Blanca de Lusiñán, mujer de Jaime II, razón por la que este monarca ordenó al baile de Calatayud que no le perturbase en el desempeño de su oficio de rabino, aunque tuviese que ausentarse con frecuencia de la ciudad para atender sus obligaciones como médico de la reina ${ }^{105}$.

En líneas generales los médicos ocuparon posiciones de primera fila en la jerarquía social de la comunidad judía bilbilitana. Así lo confirma en primer lugar el hecho de que algunos de ellos formaron parte del selecto grupo de los judíos francos, como es el caso de maestre Bayel, identificado como médico de Calatayud en $1360{ }^{106}$. Y otro interesante indicio en este mismo sentido nos lo proporcionan las pocas noticias hasta ahora reunidas sobre la identidad de los adelantados que estuvieron al cargo del gobierno de la aljama bilbilitana. Así, cabe destacar que en 1390 había entre estos oficiales, cuyo número estaba fijado en cuatro, nada menos que dos médicos, Samuel Çadoch y maestre Jacob Azarías ${ }^{107}$.

Otras noticias sueltas nos informan, además, sobre la identidad de varios médicos judíos bilbilitanos que disfrutaron de elevado prestigio y reconocimiento social, como, por ejemplo, don Todros ibn David, a quien Baer califica de miembro prominente de la comunidad judía de Calatayud a fines del siglo XIV ${ }^{108}$, o Yucé Abencabra, que se convirtió al cristianismo en los primeros años del siglo XV con el nombre de Juan Martínez de la Cabra, y recibió poco después del rey Fernando el título de caballero, y del Papa Benedicto XIII la autorización para

\footnotetext{
105 ACA, C, reg. 233, s. f., Valencia, 31-XII-1320.

106 ACA, C, reg. $699-194 \mathrm{v}$, Borja, 22-III-1360.

107 V. de la Fuente, Historia de la siempre augusta y fidelísima ciudad de Calatayud (Zaragoza 1994), vol. I, págs. 300-301.

108 Y. F. BAer, Historia de los judíos en la España cristiana. Traducción de J. L. Lacave (Barcelona 1998), pág. 347.
} 
reconvertir la sinagoga que él mismo había mandado construir en una iglesia dedicada a San Pablo ${ }^{109}$.

Además de médicos, la comunidad judía bilbilitana también contó entre sus miembros con jurisperitos. Por desgracia la documentación cancilleresca hasta ahora consultada no nos ha aportado muchas noticias que permitan profundizar en la identificación y caracterización de estos profesionales, pero al menos nos consta que los había, y que en ocasiones el rey les encargó que conociesen en determinados pleitos en los que los litigantes eran judíos ${ }^{110}$.

En cualquier caso, la relativa abundancia en la comunidad judía bilbilitana de individuos que desempeñaban profesiones para las que se requería un cierto grado de formación intelectual, puede explicarse en parte por la propia política de fomento del estudio que puso en práctica la aljama, que tuvo una de sus principales traducciones en el reconocimiento de importantes privilegios fiscales a los estudiantes. Así, sabemos que a mediados del siglo XIV estaba en vigor una ordenanza que eximía de la obligación de contribuir en el pago de impuestos de la aljama, en particular por el concepto de capitación, a todos los judíos menores de 16 años y a los que estuviesen estudiando («adisterent vel legerent eruditionem litterarum»), hasta que cumpliesen la edad de 23 años ${ }^{111}$.

\section{INTERESES DE LOS JUDÍOS BILBILITANOS EN EL SECTOR PRIMARIO: AGRICULTURA Y GANADERÍA}

La práctica totalidad de los judíos vecinos de Calatayud sobre los que disponemos de informaciones relativas a su dedicación profesional estuvieron activos

109 Vid. O. Cuella Esteban, «Los judíos bilbilitanos en tiempos del Papa Luna», en Primer Encuentro de Estudios Bilbilitanos. Actas (Calatayud 1983), vol. II, págs. 137-138. Entendemos que el Yucé Abencabra del que habla Ovidio Cuella se puede identificar con el Iucef Abencabra, físico de Calatayud, que en 1389 denunció que se le debían ciertas cuantías de dinero en Calatayud, Daroca y diversos lugares del reino de Castilla, que no podía recuperar. ACA, C, reg. 1843 28, Monzón, 1-XII-1389. Este autor no llega a afirmar expresamente que Yucé Abencabra fuese médico, aunque sí dice que lo fue, y excelente, su hijo convertido al cristianismo con el nombre de Berenguer de la Cabra, cf. ibid. pág. 138.

${ }^{110}$ Un encargo de este tipo a Rabi Huel, judío «legisperito» de la aljama de Calatayud, por Pedro IV, en ACA, C, reg. 658 - 66v, Valencia, 26-XII-1349. Otro ejemplo en reg. 783 - 75, Barcelona, 6-II-1376. Comisión a Rabí David Abenxuén, judío de Calatayud, para que conozca en todos los pleitos movidos y por mover entre Todroç Abentilca, judío de Calatayud, de una parte, y otros judíos de otra.

111 ACA, C, reg. 619 - 154, Barcelona, 6-VII-1342. Açach Çadoch, judío de Calatayud, había denunciado que se había inscrito en la lista de contribuyentes de la aljama a su hijo Çalema, a pesar de que estaba aprendiendo y no llegaba a la edad de 23 años. 
en los sectores secundario y terciario; en contrapartida no tenemos constancia explícita de que alguno de ellos se dedicase a actividades del sector primario, en concreto agricultura o ganadería, a pesar de que en la época eran las que proporcionaban ocupación a la gran masa de la población. Esto no significa, sin embargo, que no tuviesen ningún tipo de interés en estas actividades, pues, por el contrario, nos consta que al menos algunos de ellos fueron propietarios de tierras, e incluso de ganados, que, si bien no explotaban directamente, les proporcionaban rentas gracias a la cesión del derecho de su explotación a terceros.

Por lo que se refiere a ganados, no hemos encontrado hasta ahora en la documentación del siglo XIV noticias que prueben que judíos de Calatayud los poseyesen y cediesen su explotación a terceros, pero sí las hay para el siglo XV, como, por ejemplo, la relativa a Salamón Hiara, que en 1476 entregó a un moro vecino de Codes, «a guardar e partir a medias», 14 cabras y 46 ovejas, por un período de cinco años ${ }^{112}$. Muy abundantes son, por el contrario, las referencias documentales que prueban que judíos de Calatayud fueron propietarios de tierras de labranza y de viñas en el término de esta ciudad, y de sus aldeas, e incluso de otros lugares pertenecientes a otras jurisdicciones, como Ariza y Cetina ${ }^{113}$, o Villaluenga, lugar de señorío de la Orden Militar del Hospital de San Juan de Jerusalén ${ }^{114}$.

La mayoría de estas heredades fueron adquiridas por los judíos en virtud de compras efectuadas a cristianos. Y, debido a que estas operaciones llegaron a prodigarse mucho, las instituciones eclesiásticas de Calatayud y su Comunidad de aldeas consiguieron que los judíos que adquirían propiedades que anteriormente habían pertenecido a cristianos continuasen quedando obligados a satisfacer el diezmo y la primicia en las mismas condiciones que sus anteriores propietarios ${ }^{15}$. Pero en ocasiones también las adquirieron de sarracenos, como hizo

${ }^{112}$ Según contrato notarial de 26-VI-1476, publicado en F. J. García Marco, Las comunidades mudéjares de Calatayud en el siglo XV (Calatayud 1993), págs. 249-250.

113 ACA, C, reg. 134 - 223, Calatayud, 26-I-1305. Carta al justicia de Ariza para que se devuelvan a los judíos de Calatayud las heredades que algunos de ellos poseían en los términos de Ariza y Cetina, y que, según habían denunciado, les habían sido ocupadas indebidamente.

114 ACA, C, reg. 189 - 277v, Barcelona, 23-VIII-1326. Las hijas de Iucef Mantuf, judío de Calatayud, difunto, habían denunciado que, cuando vivía su padre, le habían sido ocupadas violentamente por el comendador y vecinos de Villaluenga las heredades que éste poseía en dicho lugar, que se componían de «domos, unam peciam terre ortuta salgentum et colmeta». Consta que este mismo judío era propietario de una heredad en Clares, aldea de Calatayud, de la que había sido despojado por la fuerza por el caballero García de Vera. ACA, C, reg. 131 - 112v, Calatayud, 1-III-1304.

115 ACA, C, reg. 603 - 35, Barcelona, 29-VIII-1339. El obispo de Tarazona y el cabildo de la iglesia mayor de Santa María de Calatayud habían denunciado que, aunque tenían privilegios para 
por ejemplo Iucef Abenalahud, quien compró un huerto en Saviñán a uno de los vecinos de la morería de dicho lugar, el cual le fue arrebatado por la fuerza hacia 1326 por la señora de dicha morería ${ }^{116}$.

La posesión de tierras de labranza y viñas estuvo, por lo tanto, bastante extendida entre los miembros de la comunidad judía bilbilitana, pero la abundancia de noticias sobre ataques que sufrieron estas propiedades demuestra que no les resultó en absoluto fácil mantenerlas y sacar provecho de ellas, porque, además, también nos consta que en ocasiones las autoridades municipales de los lugares donde se ubicaban las heredades aprobaron medidas de represalia contra los judíos bilbilitanos, prohibiendo a los vecinos cristianos que trabajasen en ellas. Así procedió por ejemplo hacia 1295 el concejo de Paracuellos de la Ribera, que, probablemente en represalia porque los judíos de Calatayud se negaban a pagar impuestos por las heredades que poseían en término de dicha aldea, aprobó un estatuto dirigido contra dichos judíos, en el que se disponía que nadie osase trabajar en sus heredades bajo pena de $60 \mathrm{~s}$. j. ${ }^{117}$. Y más adelante, hacia 1337, también se aprobaron medidas orientadas en el mismo sentido en el conjunto de las aldeas de la Comunidad de Calatayud, que prohibieron a todos sus vecinos no sólo trabajar en las heredades de los judíos, sino también hospedarlos o proporcionarles animales en alquiler ${ }^{118}$.

percibir diezmos y primicias de los frutos de las heredades que en origen fueron de cristianos y después pasaron a propiedad de judíos de la aljama de Calatayud, en esta ciudad y sus aldeas y en Cetina, los judíos propietarios de heredades ubicadas en tales lugares no querían pagar los dichos diezmos y primicias. En respuesta a esta denuncia el rey ordenó a sus oficiales que obligasen a los judíos a pagar.

116 ACA, C, reg. 189 - 83, Barcelona, 24-VI-1326. Carta al baile y justicia de Calatayud para que devuelvan a Iucef Abenalahud la posesión del dicho huerto.

117 ACA, C, reg. 102-28v, Gerona, 20-IX-1295. En concreto el estatuto disponía «quod nullus audeat cavare, laborare seu custodiare possessiones seu hereditates ipsorum judeorum quas habent in dicto loco de Paracuellos sub pena 60 s. j.».

118 ACA, C, reg. 592 - 18v, Castellón, 21-III-1337. Provisión dirigida a los procuradores, escribano y adelantados de los lugares de las aldeas de Calatayud, para que se suspendan ciertos estatutos y ordenanzas recientemente aprobados, que contemplaban prohibiciones ilícitas en perjuicio de los judíos de la aljama de Calatayud.

SEFARAD, vol. 67:2, julio-diciembre 2007, págs. 327-365. ISSN 0037-0894 


\section{RESUMEN}

La comunidad judía de Calatayud fue una de las más pobladas y con mayor potencial económico del reino de Aragón, tras la de Zaragoza, en la Baja Edad Media. En este artículo el autor, utilizando fundamentalmente información tomada de los registros de cancillería del Archivo de la Corona de Aragón, analiza la estructura social de dicha comunidad durante el siglo XIV. Constata la existencia de grandes diferencias de riqueza entre sus miembros, y la dedicación de éstos a muy diversas actividades económicas. Pasa revista a algunas de estas actividades, como la recaudación de impuestos de la monarquía, el préstamo de dinero, el comercio y la fabricación de paños o la práctica de la medicina.

Palabras Clave: Calatayud; Aragón; siglo XIV; comunidad judía.

\section{SUMMARY}

The Jewish community of Calatayud was one of the most populous and affluent in the kingdom of Aragon, after the community of Zaragoza, during the late Middle Ages. In this article, the author, using mainly the information that he has obtained from the Chancery Registers of the Archive of the Crown of Aragon, analyses the social structure of this community during the fourteenth century. He proves that there were important wealth differences among its members, and that they devoted themselves to a wide variety of economic activities. He gives account of some of these, namely, collection of taxes due to the king, money lending, trade, cloth manufacture and medicine.

KeYwords: Calatayud; Aragon; Fourteenth Century; Jewish Community. 